\title{
REINTERPRETAÇÃO DO COMPLEXO INTRUSIVO LAVRAS DO SUL, RS, DE ACORDO COM OS SISTEMAS VULCANO-PLUTÔNICOS DE SUBSIDÊNCIA. PARTE 1: GEOLOGIA, GEOFÍSICA E GEOCRONOLOGIA $\left({ }^{207} \mathrm{~PB} /{ }^{206} \mathrm{~PB} E \mathrm{E}^{206} \mathrm{~PB} /{ }^{238} \mathrm{U}\right)$
}

\author{
MARIA DO CARMO GASTAL ${ }^{1}$, JEAN MICHEL LAFON ${ }^{2}$, FRANCISCO JOSÉ FONSECA \\ FERREIRA ${ }^{3}$, FRANCISCO UMBERTO SIMÕES MAGRO ${ }^{4}$, MARCUS VINICIUS DORNELES \\ REMUS $^{5}$ \& CARLOS AUGUSTO SOMMER ${ }^{6}$
}

\begin{abstract}
The Lavras do Sul intrusive complex (LSIC) and coeval volcanics, formed during the Late Neoproterozoic in the Sul-Riograndense Shield, are important because they contain historic $\mathrm{Au}-\mathrm{Cu}$ occurrences. Field relationships, and gravity and magnetic data are consistent with the LSIC as nested intrusions of a volcano-plutonic subsidence system. These data also show the LSIC evolved from north to south, so we divided it into two sectors: the Tapera monzonite (TM) in the north, and the granitic body in the south. The Arroio do Jacques monzodiorite (AJM) occurs between the two sectors, surrounding the north-northeast border of the latter. TM is an intrusion emplaced during the formation and stabilization of an upper-crustal magma chamber linked to the coeval volcanics. Granites with distinct geochemical affinities form a concentric body that probably represents a resurgent pluton emplaced after some caldera collapse. Alkali-calcic granites are in the core above the main root zones, whereas alkaline granites occur as semicircular and peripheral bodies. ${ }^{207} \mathrm{~Pb} / 206 \mathrm{~Pb}$ and ${ }^{206} \mathrm{~Pb} /{ }^{238} \mathrm{U}$ ages for several LSIC-units are comparable, and confirm that the intrusive complex is a multicyclic body, probably formed over a period of ca. 23 m.y. (606-583 Ma). Nonetheless, most of LSIC-units (TM, AJM and the core granites) have similar crystallization ages, of ca. 601 and $599 \mathrm{Ma}$, suggesting that this is the major period of igneous activity forming the volcano-plutonic system. Two distinct ages were obtained for alkaline granites, ${ }^{207} \mathrm{~Pb} / 206 \mathrm{~Pb}$ age of $598 \pm 3 \mathrm{Ma}(2 \sigma)$ and ${ }^{206} \mathrm{~Pb} /{ }^{238} \mathrm{U}$ age of $586.0 \pm 2.8 \mathrm{Ma}(2 \sigma)$ respectively. Such difference in ages may be resolved if the alkaline granites were emplaced in increments. The ${ }^{207} \mathrm{~Pb} /{ }^{206} \mathrm{~Pb}$ age of $567 \pm 4 \mathrm{Ma}(2 \sigma)$ for the Jaguari Granite, situated to the west of LSIC, confirms it represents another younger alkaline event.
\end{abstract}

Keywords: Subsidence volcano-plutonic system, $\mathrm{Pb}$-evaporation dating, geochronology, gravity, magnetometry, Lavras do Sul intrusive complex.

\begin{abstract}
Resumo O Complexo Intrusivo Lavras do Sul (CILS) e vulcânicas cronocorrelatas foram formados no final do Neoproterozóico no Escudo Sul-Riograndense, e hospedam ocorrências importantes de $\mathrm{Au}-\mathrm{Cu}$. As relações de campo, e os dados gravimétricos e magnetométricos são consistentes com o fato do CILS representar intrusões agregadas de um sistema vulcano-plutônico de subsidência que evoluiu de norte para sul. Assim, o complexo intrusivo foi dividido em dois setores: monzonito Tapera (MT) no norte, e o corpo granítico no sul. O último é circundado, ao longo da borda norte-nordeste, pelo monzodiorito Arroio do Jacques (MAJ). O MT é uma intrusão posicionada durante a formação e estabilização da câmara magmática que alimentou o vulcanismo correlato. Granitos com afinidades distintas formam corpo concêntrico que provavelmente representa um pluton ressurgente posicionado após o colapso de uma caldeira. Granitos álcali-cálcicos estão no núcleo, posicionados acima das principais raízes alimentadoras, e os termos alcalinos ocorrem em corpos semicirculares e periféricos. As idades ${ }^{207} \mathrm{~Pb} /{ }^{206} \mathrm{~Pb}$ e ${ }^{206} \mathrm{~Pb} /{ }^{238} \mathrm{U}$ das diferentes unidades do CISL são comparáveis, e indicam que se trata de corpo multicíclico formado em um período de ca. $23 \mathrm{Ma}$ (606-583 Ma). Contudo, as idades de cristalização da maioria das unidades (MT, MAJ e granitos do núcleo) são similares, ca. 601 a 599 Ma, o que sugere que este foi o principal período de atividade ígnea. Para os granitos alcalinos foram obtidas idades distintas, ${ }^{207} \mathrm{~Pb} /{ }^{206} \mathrm{~Pb}$ de $598 \pm$ $3 \mathrm{Ma}(2 \sigma) \mathrm{e}^{206} \mathrm{~Pb} /{ }^{238} \mathrm{U}$ de $586,0 \pm 2,8 \mathrm{Ma}(2 \sigma)$. Tal divergência pode ser compatibilizada, se a colocação destes granitos ocorreu em incrementos. A idade ${ }^{207} \mathrm{~Pb} /{ }^{206} \mathrm{~Pb}$ de $567 \pm 4 \mathrm{Ma}(2 \sigma)$ do Granito Jaguari, que ocorre a oeste do CILS, confirma que representa um evento ígneo mais jovem.
\end{abstract}

Palavras-chave: Sistema vulcano-plutônico de subsidência, Datação por evaporação de $\mathrm{Pb}$, Geocronologia, Gravimetria, Magnetometria, Complexo intrusivo Lavras do Sul.

INTRODUÇÃO Nos arredores de Lavras do Sul (RS), ocorre uma gama de rochas intrusivas correlacionadas a traquiandesitos de idade neoproterozóica ( $600 \mathrm{Ma}$ ). A intrusão principal equivale ao complexo granítico de Lavras (Nardi 1984), que foi reavaliado por Gastal et al. (2006). Os termos menos diferenciados (monzonito-monzodioritos), situados a norte deste corpo granítico, foram anteriormente denominados e interpretados de forma diversa, a saber: complexo quartzo monzonítico-riodacítico correlacionado à Formação Acampamento Velho (Santos et al. 1989), e charnoquito Arroio do Jacques correlacionado a granulitos regionais de idade paleoproterozóica/ neoarqueana
(DeRos \& Fernandes 1981). Tais interpretações foram descartadas com base nas relações de campo, petrografia e geoquímica por Lima (1995) e Gastal (1998). Os granitos e essas rochas intermediárias ocupam a mesma estrutura intrusiva, sugerindo que estão relacionados à evolução de um único centro vulcanoplutônico. Assim, é mais apropriado incluir este conjunto de rochas na mesma unidade geológica, que foi denominada de complexo intrusivo Lavras do Sul - CILS por Gastal (1998). Neste, as rochas intermediárias constituem corpos mapeáveis, referidos informalmente de monzonito Tapera- MT e monzodiorito Arroio do Jacques - MAJ. Diques de composição varia-

1 - Centro de Estudos em Petrologia e Geoquímica, Instituto de Geociências, UFRGS, caixa postal 15 022, Porto Alegre, RS, 91 501-970, Brasil, e-mail: maria.gastal@ufrgs.br

2 - Pará-Iso, Centro de Geociências, UFPA, caixa postal 8608, Belém, PA, 66 075-110, Brasil, e-mail: lafonjm@ufpa.br

3 - Laboratório de Pesquisas em Geofisica Aplicada, Departamento de Geologia, UFPR, caixa postal 19 001, Curitiba, PR, 81531-980, Brasil, e-mail: francisco.ferreira@ufpr.br 4 - Departamento de Geodésia, Instituto de Geociências, UFRGS, caixa postal 15 001, Porto Alegre, RS, 91501-970, Brasil, e-mail: francisco.magro@ufrgs.br

5 - Centro de Estudos em Petrologia e Geoquímica, Instituto de Geociências, UFRGS, caixa postal 15 001, Porto Alegre, RS, 91 501-970, Brasil, e-mail: marcus.remus@ufrgs.br

6 - Centro de Estudos em Petrologia e Geoquímica, Instituto de Geociências, UFRGS, caixa postal 15 001, Porto Alegre, RS, 91 501-970, Brasil, e-mail: casommer@sinos.net 
da, incluindo minetes e espessartitos, secionam as intrusivas, e mineralizações de $\mathrm{Au}-\mathrm{Cu}$ ocorrem em veios de quartzo na seqüência vulcânica encaixante e no corpo granítico do CILS (Reischel 1980).

A natureza epizonal e multicíclica, e a geometria das intrusões que compõem o CILS permitem compará-lo a porções subvulcânicas e plutônicas de estruturas de subsidência de caldeiras, como referido inicialmente por Nardi (1984). O propósito deste trabalho é o de iniciar a análise integrada do arcabouço evolutivo deste centro vulcano-plutônico, reunindo as informações geológicas, geofísicas, petrográficas, geoquímicas e isotópicas para as diferentes intrusivas, as quais são comparadas às de vulcânicas cronocorrelatas. Face ao volume de informações, incluindo dados compilados da literatura, este trabalho é dividido em duas partes. Na primeira, são discutidas a estruturação e geocronologia do CILS. Esta parte reúne os aspectos gerais da geologia, geofísica e petrografia. São apresentadas as idades ${ }^{207} \mathrm{~Pb} /{ }^{206} \mathrm{~Pb}$ para granitóides do CILS e MAJ, e reavaliadas as idades ${ }^{206} \mathrm{~Pb} /{ }^{238} \mathrm{U}$ disponíveis para os primeiros (Leite et al. 1998, Remus et al. 2000). Para o granito Jaguari - GJ, situado a oeste do CILS, discute-se também a idade ${ }^{207} \mathrm{~Pb} /{ }^{206} \mathrm{~Pb}$ em base a novos dados analíticos, com intuito de confirmar as diferenças deste com os termos de mesma afinidade do CILS (Gastal \& Lafon 1998). A segunda parte do trabalho sintetiza os dados de química mineral, litogeoquímicos e isótopos de $\mathrm{Pb}-\mathrm{Sr}-\mathrm{Nd}$.

\section{GEOLOGIA REGIONAL}

Aspectos gerais Lavras do Sul está situada no oeste do Escudo Sul-riograndense, no domínio do Arco São Gabriel, próximo ao limite com a borda cratônica - Bloco Taquarembó (Fig. 1). As unidades regionais incluem seqüências metavulcano-sedimentares e ultramáficas, secionadas por metagranitóides cálcioalcalinos baixo- a médio- $\mathrm{K}$, todos formados durante a orogênese acrescionária São Gabriel (900-700 Ma) (Babinski et al. 1996). Duas descontinuidades magnéticas, equivalentes a zonas de fatha de escala regional (Costa 1997), marcam os limites do Arco São Gabriel. A Sutura de Caçapava de direção N40 $\mathrm{E}$, situada a leste, coincide com o sistema de falhas transcorrente levógiro Irapuá (Ribeiro et al. 1966); e a sul, o Lineamento de Ibaré, com direção $\mathrm{N} 45^{\circ} \mathrm{W}$, é um sistema transcorrente dextral (Porcher \& Lopes 2000).

O magmatismo pós-colisional relacionado à orogênese Dom Feliciano (660-550 Ma), e contemporâneo à deposição na Bacia de Camaquã (606-450 Ma), está amplamente representado na região. Dois eventos principais são identificados no oeste do escudo, distintos em idade e geoquímica (Gastal \& Lafon 1998). O evento precoce, $c a$. $606-580 \mathrm{Ma}$, inclui rochas vulcânicas e plutônicas shoshoníticas e granitos alcalinos. $\mathrm{O}$ evento tardio, ca. 575-550 Ma, compreende granitóides e vulcânicas ácidas de afinidade alcalina, e granitóides cálcio-alcalinos alto-K. O CILS e vulcânicas cronocorrelatas (Formação Hilário) representam a

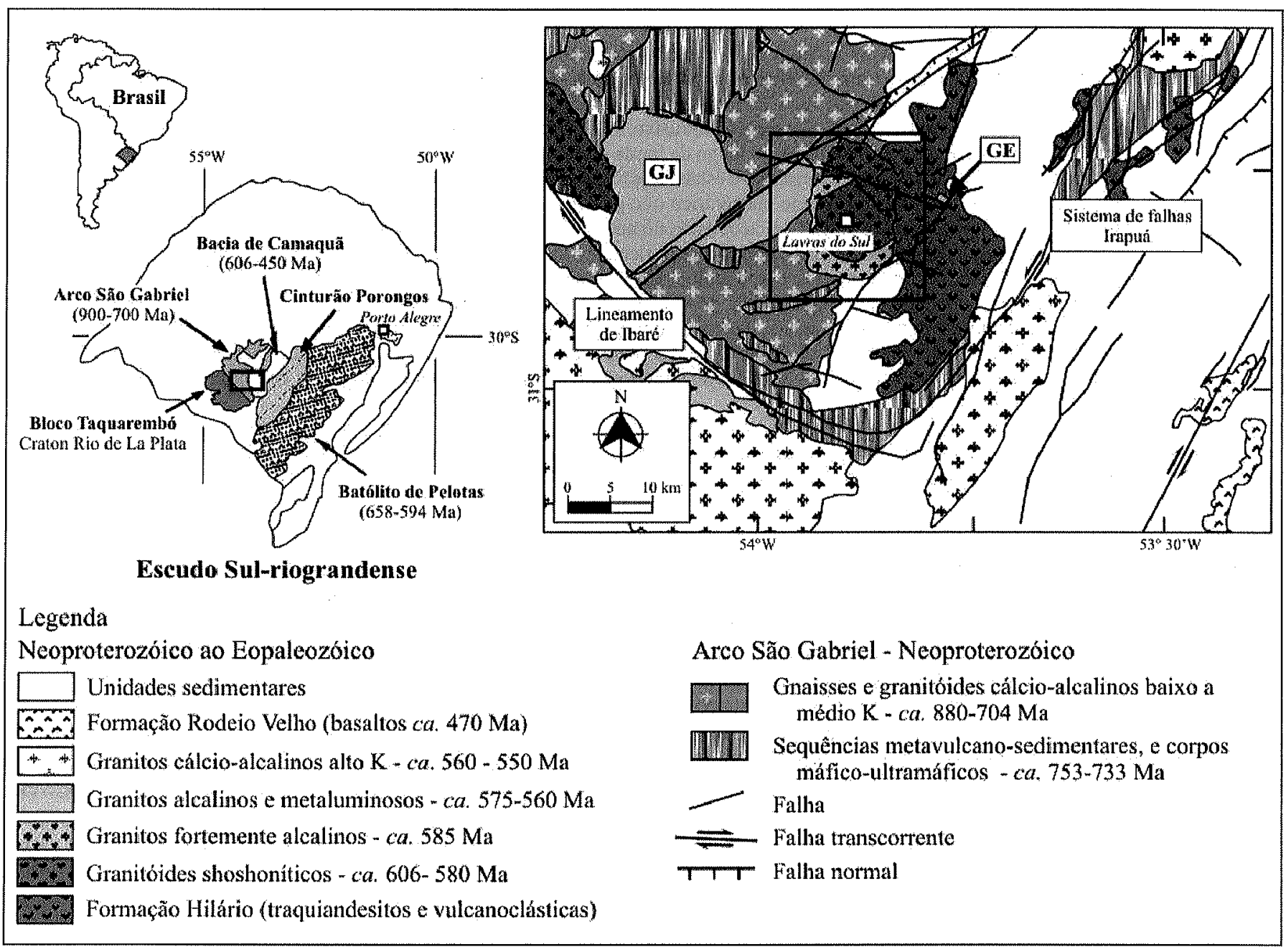

Figura 1-Esboço da geologia da região do complexo intrusivo Lavras do Sul e granito Jaguari - GJ (GE - granito Estrela), com a delimitação da área detalhada na figura 2 (modificado de Porcher \& Lopes 2000). Compartimentos geotectônicos do Escudo Sul-riograndense são mostrados a esquerda. 


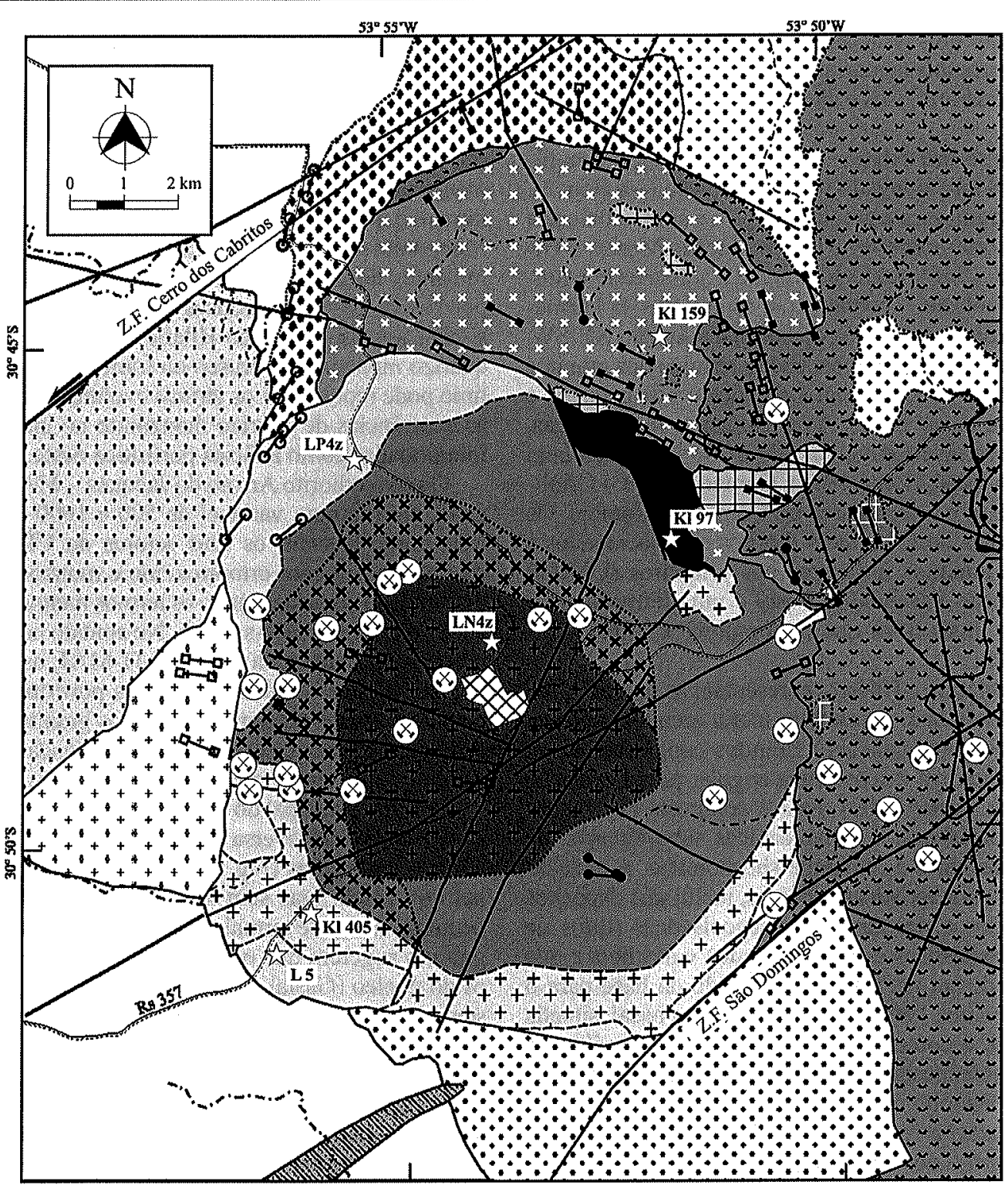

Legenda

1.:? Granito Jaguari

\section{Complexo Intrusivo Lavras do Sul}

Granitos alcalinos

\begin{tabular}{|c|c|c|}
\hline 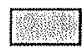 & Pertita granito & \\
\hline+1 & Sienogranito & \\
\hline Granit & óides shoshoníticos & \\
\hline & Granodiorito & \\
\hline & Sienogranito híbrido & \\
\hline & Monzogranito híbrido & \\
\hline 1. & Quartzo monzonito & \\
\hline & Monzodiorito Arroio do Jacques & \\
\hline & Monzonito Tapera & \\
\hline$\otimes$ & Mina de Au inativa & \\
\hline$\hat{s}$ & Amostra $\left({ }^{206} \mathrm{~Pb} /{ }^{238} \mathrm{U} \mathrm{e}^{201} \mathrm{~Pb} /{ }^{206} \mathrm{~Pb}\right)$ & \\
\hline & $\begin{array}{l}\text { Contato } \\
\text { Contato transicional } \\
\text { Contato inferido }\end{array}$ & $\begin{array}{l}\text { Falha e fratura } \\
\text { Falha transcorrente }\end{array}$ \\
\hline
\end{tabular}

\section{Formação Hilário}

56rer. Conglomerado

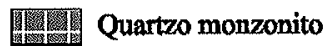

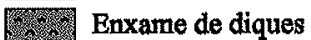

Efusivas e vulcanoclásticas $\because \because$ Formação Maricá

+ + Granodiorito Fazenda do Posto Ofiolito Cerro Mantiqueira

D. Complexo Cambar e granitóides associados (diorito)

\section{Diques}

-Traquiandesito e espessartito

$\longrightarrow$ Minete e biotita-andesito

a-Dacito, riodacito e quartzo monzonito

$\multimap$ Riolito alcalino e metaluminoso

........... Estrada principal

-.... Drenagem principal

$\$$ Cidade

Figura 2 - Mapa geológico do complexo intrusivo Lavras do Sul - CILS, com a localização de amostras datadas por evaporação de Pb em zircão (neste trabalho) e U-Pb SHRIMP em zircão (Leite et al. 1998; Remus et al. 2000); inclui dados de Reischel (1980), Lima (1995), CRM (1998) e UFRGS (2003). 
principal área de exposição do evento precoce, que está situada próximo à junção dos dois principais sistemas de falhas - Irapuá e Ibaré (Fig. 1). O granito Jaguari (GJ), a oeste do CILS, representa os termos metaluminosos e alcalinos do segundo evento.

Região do complexo intrusivo O CILS é um corpo com dimensões de $12 \times 18 \mathrm{~km}$, alongado segundo direção N-S (Fig. 2). É intrusivo em ortognaisses e granitóides pré- e sin-tectônicos a oeste-sudoeste e norte-noroeste, e nas formações Maricá e Hilário (Ribeiro et al. 1966), respectivamente a sul-sudeste e nordeste, e a leste. A sudeste, o contato com os arenitos da Formação Maricá é controlado pela zona de falhas de direção NE-SW, aqui denominada de São Domingos. Efeito térmico dos granitos do CILS é registrado na seqüência vulcânica e nos gnaisses e arenitos (Hartmann et al. 2000). As encaixantes mais antigas, com idades U-Pb variáveis entre ca. 879 e $733 \mathrm{Ma}$, estão bem caracterizadas a sudoeste (Leite 1997). Compreendem o Ofiolito Cerro Mantiqueira e ortognaisses do Complexo Cambaí. Os granitóides situados a norte incluem dioritos correlacionados a esse complexo, e tonalitos intrusivos nos primeiros (UFRGS 2003). O granodiorito Fazenda do Posto é uma intrusão sin a tardi-transcorrente, mais nova que o Complexo Cambaí (Porcher \& Lopes 2000).

As formações Maricá e Hilário representam às unidades basais da Bacia de Camaquã. A primeira inclui arenitos arcoseanos a subarcoseanos, intercalados a arenitos conglomeráticos, que estão sobrepostos em discordância angular pela Formação Hilário (Porcher \& Lopes 2000). Esta é composta por rochas efusivas e vulcanoclásticas, e subvulcânicas subordinadas, de composição intermediária e afinidade shoshonítica. A seqüência vulcânica, com características subáreas, inclui seis depósitos efusivos intercalados a pacotes de vulcanoclásticas (tufos de queda, brechas piroclásticas e conglomerados vulcânicos), que estão distribuídos de sul para norte no sentido da base para o topo da seqüência (Lima 1995). A unidade efusiva basal, situada a sudeste do CILS, é composta por traquiandesito basáltico e as demais por traquiandesito. Dentre as subvulcânicas da Formação Hilário, monzonito e quartzo monzonito são freqüentes como diques e stocks, a leste-nordeste do CILS (CRM 1998, Liz 2002). Espessartito ocorre como domos, diques e derrames restritos associados às unidades efusivas superiores (Lima \& Nardi 1991).

O granito Estrela ocorre na forma de um plug (Gastal 1998), com dimensões de $2 \times 1 \mathrm{~km}$, situado cerca de $7 \mathrm{~km}$ para nordeste do CILS e posicionado na interseção de duas zonas de falha, de direção $\mathrm{N} 75^{\circ} \mathrm{W}$ e $\mathrm{N} 30^{\circ} \mathrm{E}$ (GE - Fig. 1). É intrusivo em tufos, conglomerados vulcânicos, e em brechas piroclásticas de composição quartzo monzonítica. Inclui K-feldspato granito com arfevdsonita, e biotita sienogranito subordinado, ambos correlacionados a granitos alcalinos do CILS. O granito Jaguari (GJ) é constituído por biotita sienogranito dominante e monzogranito subordinado, todos metaluminosos e alcalinos. O contato com os termos de mesma afinidade do CILS é marcado por ampla faixa de margem resfriada félsica no GJ (Gastal \& Nardi 1992).

\section{COMPLEXO INTRUSIVO LAVRAS DO SUL - CILS}

Geologia OCILS pode ser dividido em dois setores. No norte está o monzonito Tapera, e o setor sul consiste no corpo granítico circundado parcialmente a norte-nordeste pelo monzodiorito Arroio do Jacques (Fig. 2). O monzonito Tapera - MT é uma intrusão em forma de meia-lua constituída por quartzo monzonito, monzonito, monzodiorito e diorito, os quais exibem zonação normal (Lima 1995, UFRGS 2003). Seus limites estão marcados pela abundância de diques intermediários a ácidos, com direções WNW-ESE a NNW-SSE no norte-nordeste, e dispostos segundo zona de falha de direção $\mathrm{N} 75^{\circ} \mathrm{W}$ no sul. A noroeste e a nordeste, enxame de diques, com espessura de 200 a $500 \mathrm{~m}$, marcam o contato do corpo (Fig. 2). Estes incluem feno-andesitos correlacionáveis aos da Formação Hilário, e são secionados pelos monzonitos. $\mathrm{O}$ diorito ocorre em lentes descontínuas preferencialmente associadas aos enxames de diques. Exibe foliação magmática paralela aos limites do corpo, dada pelo alinhamento dimensional de plagioclásio. A leste-sudeste, o diorito é intrusivo nas lavas traquiandesíticas, contendo xenólitos destas. Monzonito e monzodiorito, mais isotrópicos, são os termos dominantes na porção central da intrusão. Estes são secionados por stocks, diques e apófises de quartzo monzonito porfirítico, similar aos da Formação Hilário. O contato entre monzonito e quartzo monzonito é brusco ou transicional, de modo que o último pode representar os termos evoluídos do MT. Desta forma, as ocorrências de quartzo monzonito no interior do MT foram interpretadas como a fácies porfirítica deste.

O monzodiorito Arroio do Jacques - MAJ é um corpo alongado, com largura variável de 500 a $1000 \mathrm{~m}$, e posicionado a leste-nordeste entre os dois setores do CILS (Fig. 2). Inclui diorito (gabro) com ortopiroxênio e monzodiorito, que exibem distribuição zonada estando os termos menos diferenciados situados no extremo leste-sudeste. No contato nordeste, ocorre tipos híbridos sugestivos da mistura MT-MAJ, os quais são secionados por diques e apófises da fácies porfirítica do MT. A sul, o contato é brusco ou por falha com os granitos do núcleo e marcado por pequena faixa de margem resfriada félsica nos granitos alcalinos, que também ocorrem em apófises no MAJ.

O corpo principal do CILS é uma intrusão granítica centrada com zonalidade reversa de fácies, álcali-cálcicas (granitos do núcleo) e alcalinas (Fig. 2). O contato entre fácies é transicional ou brusco, mas sem afinamento da granulação, indicando pequeno contraste termal. As relações de campo e feições petrográficas sugerem que os granitos alcalinos são mais jovens que os do núcleo (Gastal et al. 2006). Os primeiros formam corpos semicirculares e stocks periféricos, e exibem ocorrência polarizada: biotita-anfibólio sienogranito (BAS) a sul-sudeste, e pertita granito $(\mathrm{PG})$ a oeste-noroeste. Os termos do núcleo incluem dois grupos de fácies. Biotita granodiorito $(\mathrm{BG})$ na porção central, circundado pelo anfibólio-biotita monzogranito (ABM). O primeiro exibe variações texturais devido a exsolução de voláteis, e é aparentemente mais novo que o ABM. O monzogranito evolui para sienogranito e exibe leve afinamento da granulação no sentido centro-borda. Os termos menos evoluídos destes, com enclaves microgranulares freqüientes, estão concentrados a oeste e norte (Fig. 2). Nesta região, ocorrem também xenólitos de rochas correlacionáveis ao MT-MAJ, e de lápili-tufo constituído por piroclastos de efusivas e subvulcânicas correlatas e de granitóides (Fig. 3A). Independente da origem, a presença destas rochas como xenólitos no ABM corrobora a idéia de que esta fácies representa a borda de uma intrusão precoce na construção do pluton.

No conjunto, observa-se a mudança na composição de diques no sentido da evolução do CILS. No setor norte, os diques incluem traquiandesito similar às lavas Hilário, quartzo monzonito, e biotita-clinopiroxênio andesito (Fig. 3B), espessartito e riolito subordinados. Riodacito e dacito formam diques (WNWESE a ENE-WSW) nos granitos do núcleo, e diques de riolito (NE-SW), composicionalmente relacionado ao GJ, ocorrem no pertita granito a noroeste (Fig. 2). Minetes ocorrem em diques estreitos $(20-80 \mathrm{~cm})$, com direção $\mathrm{N} 85^{\circ}-60^{\circ} \mathrm{W}$, nos granitos híbridos. Estes exibem contatos ondulados a regulares, indicando certa contemporaneidade com os granitos encaixantes. Lamprófiros mistos, possivelmente resultantes da mistura espessartitominete, ocorrem no MT (Fig. 3C).

Geofísica São realçadas a seguir as feições gravimétricas e 

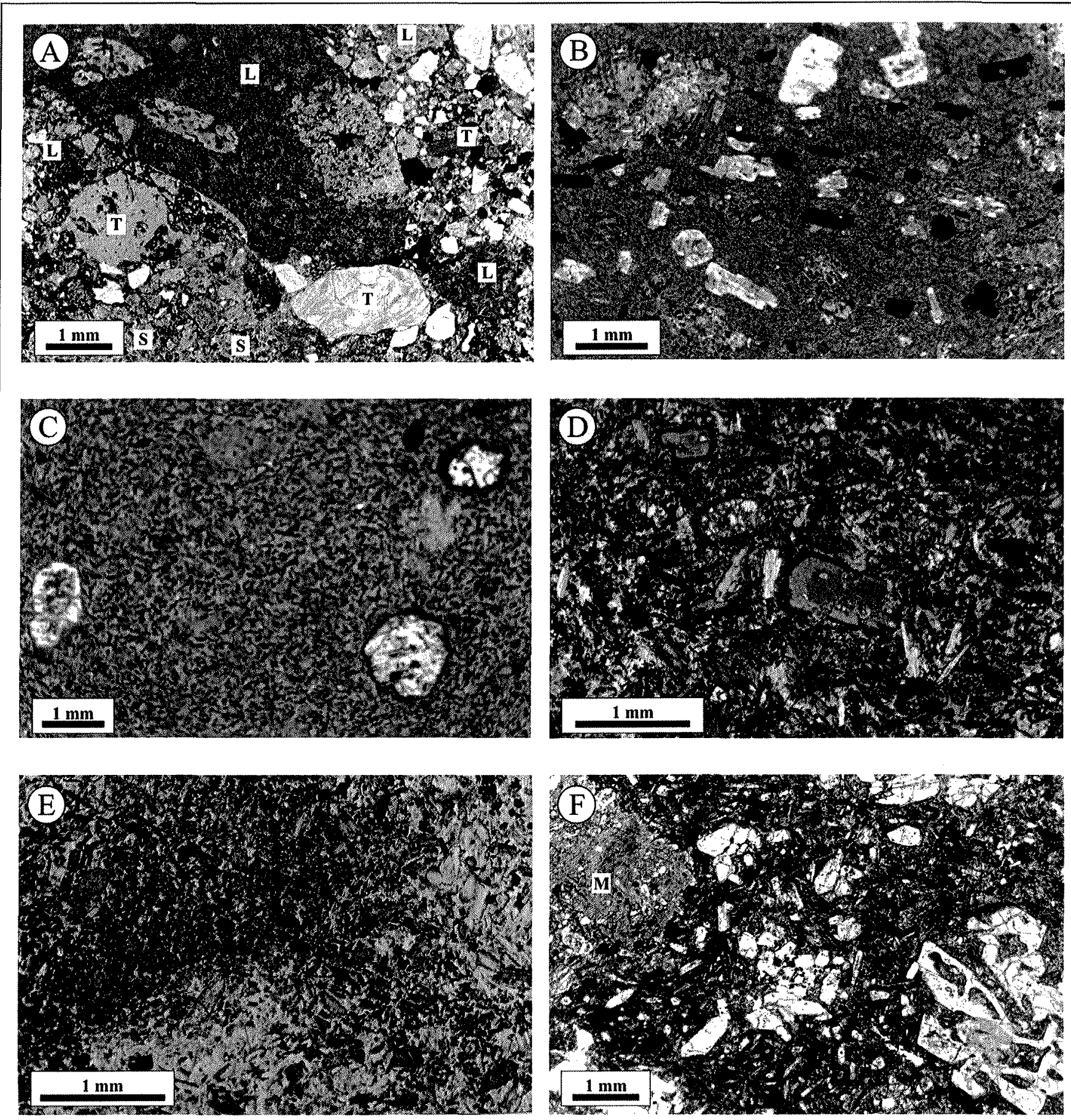

Figura 3-Fotomicrografias (LN): A-Lápili-tufo (Kl 653), como xenólito no sienogranito híbrido do CILS. Litoclastos de lava (L), tufos (T) e subvulcânicas (S), cristaloclastos de quartzo e plagioclásio, e matriz tufácea; $B$-Biotita-clinopiroxênio andesito (L151), em dique no monzonito Tapera (MT). Biotita em lamelas subédricas a euédricas, e matriz cripto a microcristalina; $C$ - Lamprófiro misto em dique no MT (L83). Fenocristais de clinopiroxênio e feldspato potássico, em matriz microcristalina composta por biotita, anfibólio e plagioclásio; D-Minete (Kl 647E), contendo fenocristais e microfenocristais abundantes de flogopita e Cr-diopsidio, e matriz microcristalina; $E$-Porções de vogesito em contato com o minete (Kl 647E). Microfenocristais de kaersutita/Fe-pargasita no vogesito, concentrados ao longo do contato que é irregular. Aqui, o minete consiste de microfenocristais de flogopita e aglomerados de feldspato ternário, com Fe-pargasita e flogopita na matriz; e F-Olivina minete (Kl 647A), com fenocristal esqueletal de olivina, microfenocristais de olivina e flogopita, e matriz criptocristalina a vitrea; $M$ - microxenólito de clinopiroxenito. Os três últimos ( $D$ a F) em diques nos sienogranitos híbridos do CILS.

magnéticas qualitativas mais significativas, discutidas em detalhe por Ferreira et al. (em preparação). Uma síntese sobre a aquisição e processamento destes dados é fornecida no apêndice.
GRAVIMETRIA No mapa de anomalias Bouguer (Fig. 4A), os valores variam de $14,9 \mathrm{a}-23,1 \mathrm{mGal}$, decrescendo para oeste. $\mathrm{O}$ gradiente nas curvas de isovalores é acentuado a nordeste-lestesudeste, delineando os limites do CILS. Contudo, fortes con- 


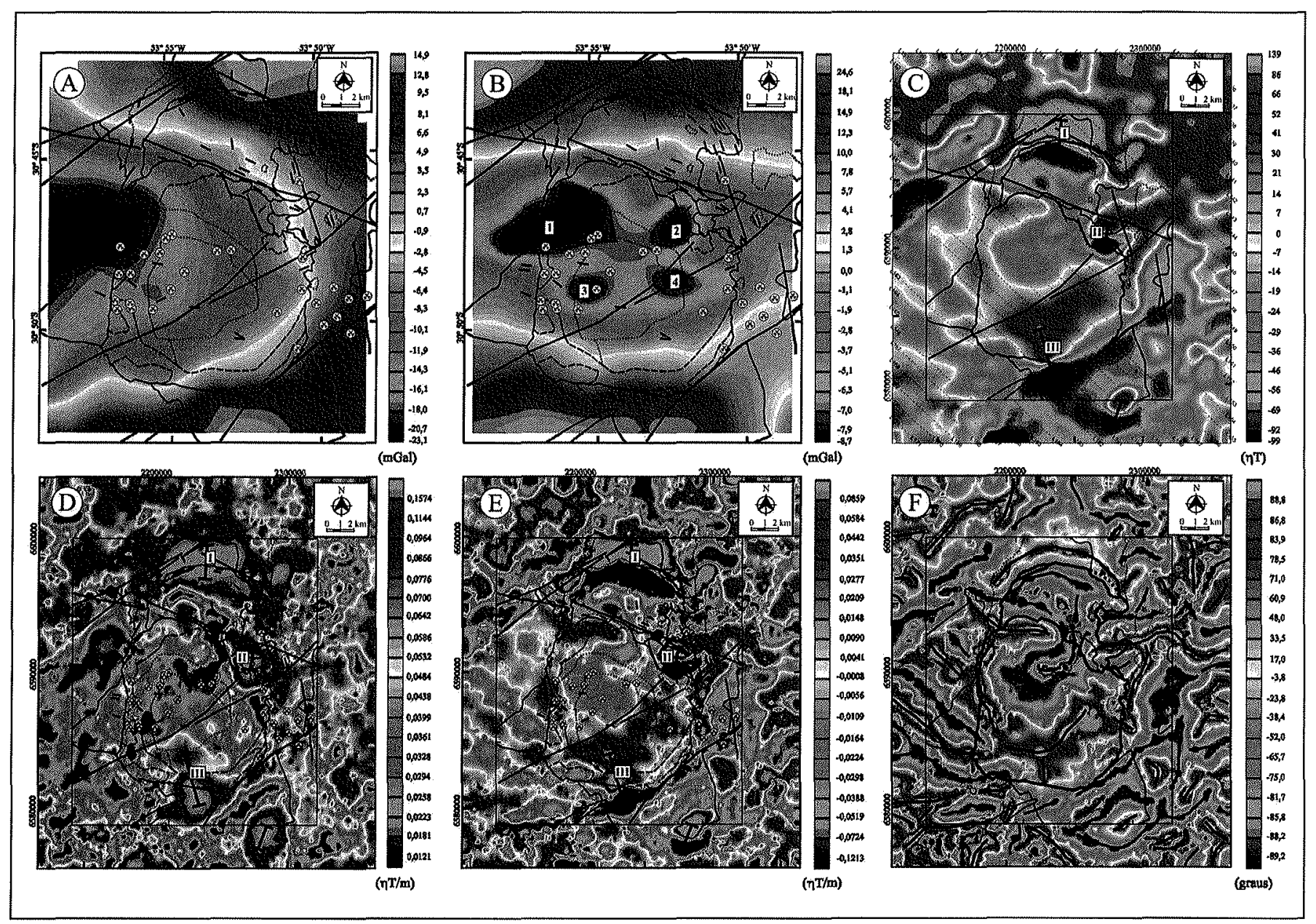

Figura 4-A-Mapa de anomalias Bouguer; B - Mapa gravimétrico residual, realçando os principais baixos gravimétricos $(<$ -7,9 $\mathrm{mGal)}$ no centro do corpo granítico do CILS (1 a 4); C - Mapa magnético residual e linhas de vôo; $D$ - Mapa magnético da amplitude do sinal analítico; $E$ - Mapa magnético do gradiente vertical; e F - Mapa magnético da fase do sinal analítico, que salienta as estruturas rasas (dados magnéticos originais de Jackson et al. 1973). Mapas estão sobrepostos com o contorno das unidades geológicas, diques e minas de Au-Cu inativas, como mostrado na figura 2; em $C$ e F, os detalhes foram retirados e, em $F$, são mostrados os principais lineamentos magnéticos (azul-altos e vermelho-baixos); barra (C-E) identifica as principais anomalias magnéticas dipolares, sendo três localizadas nos limites do CILS (I a III).

trastes no mapa gravimétrico residual marcam apenas os limites norte e sul-sudeste (Fig. 4B), devido a altos gravimétricos nas encaixantes. A assinatura negativa do corpo granítico do CILS é bem evidenciada nesse mapa, que também revela quatro baixos principais que expressam o posicionamento das raizes alimentadoras da intrusão. Tais baixos, numerados de 1 a 4 (Fig. 4B), exibem distribuição simétrica. Dois estão localizados a norte, próximo aos limites (1 e 2), e dois na porção central do corpo granítico ( 3 e 4). O primeiro com forma alongada segundo direção NE-SW é o de maior dimensão e amplitude. Devido a estar localizado nas proximidades do contato CILS-GJ, sua origem é ambígua, uma vez que pode estar associado ao posicionamento de qualquer uma das duas intrusões. Os três outros baixos gravimétricos são mais circulares, e estão relacionados à colocação dos granitos do núcleo. A conexão dos baixos 3 e 4 segundo alinhamento de direção W-E é realçada nos mapas gravimétricos da fase do sinal analítico e do gradiente horizontal (Ferreira et al. em preparação). Este alinhamento, no centro do pluton granítico, coincide com a região onde estão concentrados os diques de dacito-riodacito e as mineralizações de $\mathrm{Au}-\mathrm{Cu}$ (Figs. 2 e 4B). Deste modo, pode representar importante zona de fraturas profundas que condicionou o ascenso dos magmas graníticos. Entretanto, os alinhamentos de direção NE-SW unindo os bai- xos 2 e 3 são também significativos (Fig. 4B). Em profundidade, as quatro raízes coalescem em um único baixo central, como evidenciado nos mapas gravimétricos continuados para cima (Ferreira et al. em preparação). Isto sugere forma afunilada em profundidade para o corpo granítico do CILS.

MAGNETOMETRIA. No mapa magnético residual, são realçadas as seguintes feições (Fig. 4C): (1) altos magnéticos com padrão semicircular marcando os limites do CILS a norte-nordeste-leste e a oeste-sul-sudeste; (2) baixo magnético relativo no centro do corpo granítico, reforçando a idéia de que sob esta região estão as principais raízes alimentadoras do pluton central; (3) duas estruturas magnéticas bidimensionais, sub-paralelas e orientadas segundo direção NE-SW, que balizam os limites do CILS a noroeste e sudeste, e são coincidentes com as principais zonas de falha, respectivamente, Cerro dos Cabritos e São Domingos (Fig. 2); (4) quatro anomalias magnéticas aproximadamente dipolares, sendo três posicionadas ao longo dos limites do CILS (I a III); e (5) estrutura magnética bidimensional de menor amplitude, orientada segundo direção WNW-ESE, marcando a separação dos dois setores do CILS: MT a norte, e granitos e MAJ a sul (Fig. 2). Esta estrutura está bem caracterizada em profundidade e, nos níveis superficiais, ela é interrompida e des- 
locada pelos lineamentos de direção NE-SW e N-S (Fig. 4F).

O contorno do complexo intrusivo, a norte-nordeste-leste, é marcado por altos magnéticos relativos nas encaixantes, como evidenciam os mapas magnéticos da amplitude do sinal analítico e do gradiente vertical (Figs. 4D-E). Este padrão, concordante ao registrado pelas anomalias Bouguer (Fig. 4A), sugere contato abrupto do CILS com as vulcânicas correlatas e os arenitos Maricá. Por outro lado, os altos magnéticos que delimitam o contorno do CILS a oeste-sudoeste-sul estão no domínio dos granitos, próximo ao contato entre os tipos com afinidades contrastantes (álcali-cálcico e alcalino). Este padrão semicircular é bem evidenciado nos mapas magnéticos do gradiente vertical e da fase do sinal analítico (Figs. 4E-F), sendo também concordante com a zonalidade reversa nos valores de susceptibilidade magnética dos granitos (Gastal et al. 2006). Assim, tal padrão parece estar vinculado ao posicionamento dos granitos periféricos e alcalinos ao redor do pluton central. Nessa região, são freqüentes enclaves microgranulares e máficos, indicativos da mistura de magmas básico e granítico. Pode-se especular, então, que esse alinhamento semicircular se deva em parte à presença de rochas máficas em profundidade. A forma do MT é controlada por anomalia magnética bipolar de grande amplitude (I - Figs. 4C-E), e por zona de falha de direção WNW-ESE a sul. A anomalia bipolar, a norte, exibe um padrão semicircular perfeito nos níveis superficiais (Fig. 4F) e, em profundidade, torna-se mais estreita e deslocada para sul (Ferreira et al. em preparação). Esta forma cônica do MT permite inferir que se trata de intrusão tipo cone-sheet, cuja borda seria representada pelos enxames de diques (Fig. 2).

A continuidade, em profundidade, das feições magnéticas que delimitam o CILS sugere que a estruturação é mantida por cerca de 1,5-2,0 km (Ferreira et al. em preparação). É possível concluir que o CILS, como um todo, tem forma levemente afunilada em profundidade e a porção superior é tabular e relativamente fina. Nos niveis superficiais, este conjunto de feições faz com que o CILS exiba um padrão singular de lineamentos magnéticos (Fig. 4F), que permite sua perfeita individualização das demais unidades geológicas, inclusive granito Jaguari.

\section{UNIDADES PLUTÔNICAS E SUBVULCÂNICAS DO} COMPLEXO INTRUSIVO - PETROGRAFIA

Monzonito Tapera $\mathrm{O}$ diorito é equigranular grosso ou médio, e no monzonito e monzodiorito predomina a textura seriada média a grossa. O último evolui a quartzo monzonito e exibe arranjo intergranular, com grãos tabulares de andesina e anédricos de quartzo e K-feldspato. Apatita e Ti-magnetita são os principais acessórios. A augita/diopsídio está presente nos tipos menos evoluídos, que contém $\mathrm{Mg}$-hornblenda e $\mathrm{Mg}$-biotita em quantidades similares. Com a evolução, o anfibólio torna-se mais precoce na cristalização, exibindo zonação normal e euédrica. Nesse sentido, a biotita decresce em abundância, e aumentam os desequilíbrios texturais (arredondamento de grãos de feldspatos, texturas rapakivis e anti-rapakivis, e poiquilomosaíco de quartzo), bem como a fração fina e intergranular.

\section{Monzodiorito Arroio do Jacques O MAJ é constituído por} diorito e monzodiorito, e evolui até quartzo monzodiorito. Todos exibem textura equigranular média, ou seriada média a fina, e incluem andesina/labradorita, Mg-augita e Mg-biotita. Grãos de K-feldspato e, mais raro, de quartzo são anédricos e intersticiais, e ilmenita e apatita são os principais acessórios. Nos termos menos evoluídos, a Fe-enstatita é comum e a Mg-biotita é relativamente tardia na cristalização. $\mathrm{Na} \mathrm{Fe}$-enstatita, lamelas de exsolução segundo (001), muito finas $(<1 \mu \mathrm{m})$, são ocasionais, sugerindo tratar-se de pigeonita invertida. A evolução é marcada pelo desaparecimento da Fe-enstatita, decréscimo de Mg-augi- ta, e natureza mais precoce na cristalização da $\mathrm{Mg}$-biotita. $\mathrm{Mg}$ hornblenda em coronas ao redor da Mg-augita, ou em escassos grãos intersticiais, está restrita aos termos mais evoluídos próximos a apófises da fácies porfirítica do MT. A actinolita é comum nos núcleos de $\mathrm{Mg}$-augita, porém a maior abundância de actinolita, biotita esverdeada e clorita ocorre em amostras situadas no contato com os granitos $(<50 \mathrm{~m})$.

Corpo granítico Os aspectos relevantes da petrografia, mineralogia e condições de cristalização dos granitos do CILS são resumidos na tabela 1, e detalhados por Gastal et al. (2006).

Os granitos do núcleo variam de biotita granodiorito - $\mathrm{BG}$ a anfibólio-biotita monzogranito- $\mathrm{ABM}$, contendo oligoclásio cálcico/andesina e percentuais de Fe-biotita iguais ou superiores aos da Fe-hornblenda. Todos exibem textura seriada fina a grossa, entretanto maior contraste na granulação ocorre no BG, que é subdividido em dois tipos: seriado que é dominante, e porfirítico subordinado. Ti-magnetita e alanita são freqüentes, e ilmenita e titanita subordinados. As texturas de desequilíbrio do plagioclásio são marcantes e sugerem a atuação diversificada de processos de hibridismo. Variações na mineralogia e texturas permitem dividir o $\mathrm{ABM}$ em dois tipos, que foram informalmente designados de monzogranito e sienogranito híbridos (Gastal et al. 2006).

Os termos alcalinos incluem biotita-anfibólio sienogranito - BAS e pertita granito - PG, contendo oligoclásio a albita cálcica, abundante albita tardia, escassa Fe-biotita, e quantidades variadas de Fe-hornblenda. Titanita rica em elementos terras raras (ETR)-Nb-Y e Ti-magnetita são os principais acessórios, e a fluorita cresce em abundância com a diferenciação. O BAS exibe textura seriada grossa a fina, com granulação bimodal, que sugere dois momentos na cristalização. $\mathrm{O}$ PG dominante possui textura equigranular média ou grossa, e varia para tipos seriados médios a finos. No primeiro, a biotita/anita é subsolidus e a Fe-hornblenda transiciona para Fe-barroisita. No PG seriado, predomina a Fe-hornblenda, a Fe-biotita é comum e a titanita é ocasional, ocorrendo em porções com pouca ou sem fluorita.

Minetes $O$ dique de maior possança é constituído por minete (Fig. 3D), que é uma rocha heterogênea, secionada por zonas centimétricas de vogesito afírico (Fig. $3 \mathrm{E}$ ). O outro dique é constituído por olivina minete, contendo microxenólitos de clinopiroxenito (Fig. 3F). O ol-minete é constituído por fenocristais e microfenocristais freqüentes de olivina, e escassos de diopsídio e Ti-flogopita, imersos em matriz intersetal. Mg-cromita ocorre em inclusões na olivina, e Ti-magnetita e apatita na mesóstasis. O minete contém fenocristais de Cr-diopsídio, Ti-flogopita e pseudomorfos de olivina (talco, carbonato e serpentina). A matriz microcristalina é composta por microfenocristais de Ti-flogopita e Cr-diopsídio, grãos muito finos de Ti-magnetita, diopsídio, Fe-pargasita, apatita, feldspato ternário, e abundante pirita e carbonato. A Ti-flogopita exibe zonação normal e direta em lamelas da matriz e microfenocristais, e inversa no núcleo de fenocristais. $O$ vogesito é constituído por microfenocristais zonados de kaersutita/Fe-pargasita e escassos de Fe-biotita, imersos em matriz micro a criptocristalina a base de feldspato alcalino (sanidina e alta albita), Ti-magnetita, pirita e cristálitos de Fe-pargasita, Fe-biotita e apatita. Agregados radiados de ripas de feldspato alcalino são freqüentes, e formam bolsões ou porções traquíticas na matriz.

\section{GEOCRONOLOGIA}

Idades ${ }^{207} \mathbf{P b} /{ }^{206} \mathbf{P b}$ As idades ${ }^{207} \mathrm{~Pb} /{ }^{206} \mathrm{~Pb}$ obtidas por evaporação de cristais de zircão em quatro amostras, três do CILS e uma do granito Jaguari, estão na tabela 2 e figura 5. Procedimentos analíticos e estatísticos, e a descrição das amostras são fornecidos no 
Tabela 1 - Sintese de feições petrográficas, mineralógicas e condições de cristalização dos granitos do complexo intrusivo Lavras do Sul.

\begin{tabular}{|c|c|c|c|c|}
\hline & \multicolumn{2}{|c|}{ Granitos do núcleo } & \multicolumn{2}{|c|}{ Granitos alcalinos } \\
\hline & Granodio rito & Monzogranito híbrido & Sienogranito & Pertita granito \\
\hline \multicolumn{5}{|c|}{ Texturas e minera logia } \\
\hline & $\begin{array}{l}\text { Seriado a porfirítico, grosso a fino. } \\
\text { Contrastes texturais e feiçбes de exsolução } \\
\text { de voláteis. } \\
\text { Zonação oscilatória do Pl (An 35-20). }\end{array}$ & $\begin{array}{l}\text { Seriado grosso a fino. } \\
\text { Feiçzes de dissoluça/corrosão do Pl e de } \\
\text { hibridismo freqüentes nos monzogranitos, } \\
\text { escassas nos sienogranitos. }\end{array}$ & $\begin{array}{l}\text { Bimodalidade textural (grossa e média). } \\
\text { Feiçðes de hibridismo restritas. } \\
\text { e Reabsorção do Pl pelo Kfs. }\end{array}$ & $\begin{array}{l}\text { Equigranular médio ou grosso: agregados de } \\
\text { Kfs ou Qtz, transição subsolvus para } \\
\text { hipersolvts. } \\
\text { Seriado grosso a fino: reabsorção do P1 pelo } \\
\text { Kfs. }\end{array}$ \\
\hline Bt:Amp. & $\geq 2: 1$ & 2:1 (monzogr.) a $1: 1$ (sienogr.) & $<1: 1$ & $<1: 1$ \\
\hline Anfibólio & $\begin{array}{l}\text { Fe-hornblenda liquidus (Fe-edenita e Mg- } \\
\text { hornblenda) }\end{array}$ & Fe-hornblenda liquidus (Mg-hornblenda) & Fe-hornblenda magmática (Fe-edenita) & $\begin{array}{l}\text { Fe-hornblenda (seriado) a Fe-barroisita } \\
\text { (equigranular), tardi-magmática a subsolidus }\end{array}$ \\
\hline $\mathrm{Fe}^{* 1}$ & $0,55-0,56$ & $0,59 \cdot 0,57$ & $0,69-0,87$ & $0,76-0,87$ \\
\hline IAG $^{\prime}$ & $0,44-0,51$ & $0,44-0,56$ & $0,66-0,77$ & $0,66-0,90$ (seriado) e $0,99-1,36$ (equigr.) \\
\hline Biotita & Fe-biotita magnática & Fe-biotita magmática & Fe-biotita tardi-magmática & $\begin{array}{l}\text { Fe-biotita/anita tardi-magmática (seriado) a } \\
\text { subsolidus (equigranular) }\end{array}$ \\
\hline $\mathrm{Fe}^{*}$ & $\quad 0,56-0,60$ & $0,58-0,62$ & $0,66-0,67$ & $0,73-0,94$ \\
\hline Titanita & Escassa e subsolidus & Tardi-magmática & Primáría e rica em ETR-Nb-Y & $\begin{array}{l}\text { Primária e rica em ETR-Nb-Y é ocasional no } \\
\text { tipo seriado }\end{array}$ \\
\hline$M(\%)^{2}$ & $5,6 \cdot 6,1$ & $7,2-6,9$ & 6 & $4,5-4,3$ \\
\hline Ti-mt: $: \operatorname{lm}^{2}$ & $3: 1$ a $5: 1$ & $10: 1$ & $\geq 20: 1$ & $\geq 20: 1$ \\
\hline \multicolumn{5}{|c|}{ Ordem de cristalização ${ }^{2}$} \\
\hline & Pl-Amp-Bt/Qtz-Kfs a Pl-Amp-Qtz/Bt-Kfs & $\mathrm{Pl} / \mathrm{Amp}-\mathrm{Bt} / \mathrm{Kfs}-\mathrm{Q} t \mathrm{a}$ a Pl/Amp-Kfs-Bt/Qtz & $\mathrm{Pl}-\mathrm{Kf} / \mathrm{Amp}-\mathrm{Qtz}-\mathrm{Bt}$ & $\mathrm{P} \mathrm{t} / \mathrm{Kf} \mathrm{f} / \mathrm{Qtz}-\mathrm{Amp}-\mathrm{Bt}$ a $(\mathrm{P} \mid)-\mathrm{Kfs}-\mathrm{Q} t \mathrm{z} / \mathrm{Amp}-\mathrm{Bt}$ \\
\hline \multicolumn{5}{|c|}{ Condiçð̃es de cristalização } \\
\hline $\mathrm{P}(\mathrm{kbar})^{3}$ & $2-3$ & 4 (monzogranito) e 2-3 (sienogranito) & $2-3$ & $\sim 1$ \\
\hline $\mathrm{H}_{2} \mathrm{O}(\%)^{4}$ & $3-4$ & $3-4$ & 2 & 1 \\
\hline Liquidus $^{4}$ & $950-900^{\circ} \mathrm{C}$ & $900-870^{\circ} \mathrm{C}$ & $970-950^{\circ} \mathrm{C}$ & $970-950^{\circ} \mathrm{C}$ \\
\hline Solidus ${ }^{4}$ & $760-750^{\circ} \mathrm{C}$ & $750-720^{\circ} \mathrm{C}$ & $750-720^{\circ} \mathrm{C}$ & $670-650^{\circ} \mathrm{C}$ \\
\hline
\end{tabular}

apêndice. Os resultados são apresentados com desvio de $2 \sigma$.

MONZONITO TAPERA E MONZODIORITO ARROIO DO JACQUES Na amostra de MT (K1 159 - Fig. 5A), cinco cristais de zircão exibem resultados satisfatórios e analiticamente similares, fornecendo a idade ${ }^{207} \mathrm{~Pb} /{ }^{206} \mathrm{~Pb}$ de $601 \pm 5 \mathrm{Ma}$ (USD $=1,8$ ). Para um grão de zircão (159/3, Tab. 2), a idade obtida é mais antiga ( $c a .612 \mathrm{Ma}$ ), porém está dentro das incertezas analíticas das demais. Deste modo, excluindo este grão, obtém-se idade similar de 599,2 $\pm 4,4 \mathrm{Ma}$ (USD = 1,3). Cinco cristais de zircão da amostra do MAJ (K1 97 - Fig. 5B) forneceram a idade ${ }^{207} \mathrm{~Pb} /{ }^{206} \mathrm{~Pb}$ de $599 \pm 7 \mathrm{Ma}(\mathrm{USD}=2,6)$. $\mathrm{O}$ valor do USD indica dispersão dos pontos analíticos, provocada provavelmente pelo grão K197/8 com idade mais antiga, de $607 \pm 4$ Ma (Tab. 2). Com a eliminação deste grão, é obtida idade média de $593 \pm$ $4 \mathrm{Ma}$ (USD $=0,9$ ). Por outro lado, os steps com idades mais jovens ( $\leq 590 \mathrm{Ma}$ ) são de grãos fraturados que poderiam ter sofrido perda de $\mathrm{Pb}$ radiogênico (97/2 e 97/4, Tab. 2). Então, duas interpretações são possíveis para a idade de cristalização do MAJ: a) $599 \pm 7 \mathrm{Ma}$; ou b) $593 \pm 4 \mathrm{Ma}$, com cristais de zircão herdados $(\sim 607 \mathrm{Ma})$. Na ausência de argumentos convincentes, optou-se pela primeira alternativa. As idades ${ }^{207} \mathrm{~Pb} /{ }^{206} \mathrm{~Pb}$ do MT e MAJ, respectivamente $601 \pm 5$ Ma e $599 \pm 7$ Ma, são idênticas dentro das incertezas analíticas, e podem ser interpretadas como de cristalização das duas unidades menos evoluídas do CILS. Isto corrobora a contemporaneidade no posicionamento destas rochas sugerida pelas relações de campo.

BIOTITA ANFIBÓLIO SIENOGRANITO Oito cristais de zircão da amostra de biotita-anfibólio sienogranito - BAS (K1 405 - Fig. 5C) forneceram a idade ${ }^{207} \mathrm{~Pb} /{ }^{206} \mathrm{~Pb}$ de $598 \pm 3 \mathrm{Ma}$ (USD $=2,6$ ). Dos oito, três cristais exibem idades superiores a $600 \mathrm{Ma}$, sendo que em um o erro analítico é elevado (405/3, Tab. 2). Ex- cluindo este cristal, ou os três com idades superiores a $600 \mathrm{Ma}$, são obtidas idades similares ( $c a .599,6$ e 596,5 Ma). A idade de $598 \pm 3 \mathrm{Ma}$, interpretada como de cristalização do BAS, é consistente com as idades ${ }^{207} \mathrm{~Pb} /{ }^{206} \mathrm{~Pb}$ do MT e MAJ (601-599 Ma). Isto sugere que o BAS e o MT-MAJ foram formados durante um mesmo evento ígneo ou em episódios muito próximos (601$598 \mathrm{Ma})$. Porém, estas idades são distintas das idades ${ }^{206} \mathrm{~Pb} /{ }^{238} \mathrm{U}$ ( 594 e $583 \mathrm{Ma})$ obtidas para os granitos do CILS por Remus et al. (2000) e Leite et al. (1988), discutidas a seguir (Tab. 3).

GRANITO JAGUARI A amostra datada é a mesma estudada por Gastal \& Lafon (1998), que obtiveram a idade ${ }^{207} \mathrm{~Pb} /{ }^{206} \mathrm{~Pb}$ de $565 \pm 55 \mathrm{Ma}$ em quatro cristais de zircão, utilizando o método modificado de Kober (1986) por evaporação direta de $\mathrm{Pb}$ (Gaudette et al. 1998). Nove cristais de zircão exibem resultados analiticamente similares, porém mais precisos. Forneceram a idade ${ }^{207} \mathrm{~Pb} /{ }^{206} \mathrm{~Pb}$ de $567 \pm 4 \mathrm{Ma}(\mathrm{USD}=1,7)(\mathrm{Tab} .2$ e Fig. 5D), que confirma que este granito é mais jovem que o CILS com o qual faz contato. As idades ${ }^{207} \mathrm{~Pb} /{ }^{206} \mathrm{~Pb}$ mais antigas $(582-576 \mathrm{Ma})$, em steps na amostra do GJ (131/9,11 e 14, Tab. 2), são analiticamente menos precisas. Isto enfraquece o possível vínculo do GJ com os eventos finais na evolução do CILS (Tab. 3). Utilizando metodologia distinta, as idades mais antigas ( $\sim 674 \mathrm{Ma})$ sugestivas de núcleos herdados de zircão, obtidas anteriormente (Gastal \& Lafon 1998), não foram confirmadas.

Idades ${ }^{206} \mathbf{P b} /{ }^{238} \mathbf{U}$ Remus et al. (2000) dataram zircões dos dois extremos composicionais dos granitos (Tab. 3): (1) pertita granito (PG) seriado (LP4z - Fig. 2); e (2) biotita granodiorito (BG) localizado em um dos bolsões do tipo porfirítico (LN4z - Fig. 2). Nas duas amostras, os zircões exibem núcleos maciços e bordas com zonação concêntrica e oscilatória. Em ambas, os autores obtiveram idades ${ }^{206} \mathrm{~Pb} /{ }^{238} \mathrm{U}$ similares, de $c a .594 \mathrm{Ma}$ 
Tabela 2 - Resultados analíticos obtidos por evaporação de Pb em cristais de zircão do complexo intrusivo Lavras do Sul (monzodiorito Arroio do Jacques, monzonito Tapera e biotita-anfibólio sienogranito alcalino) e do granito Jaguari.

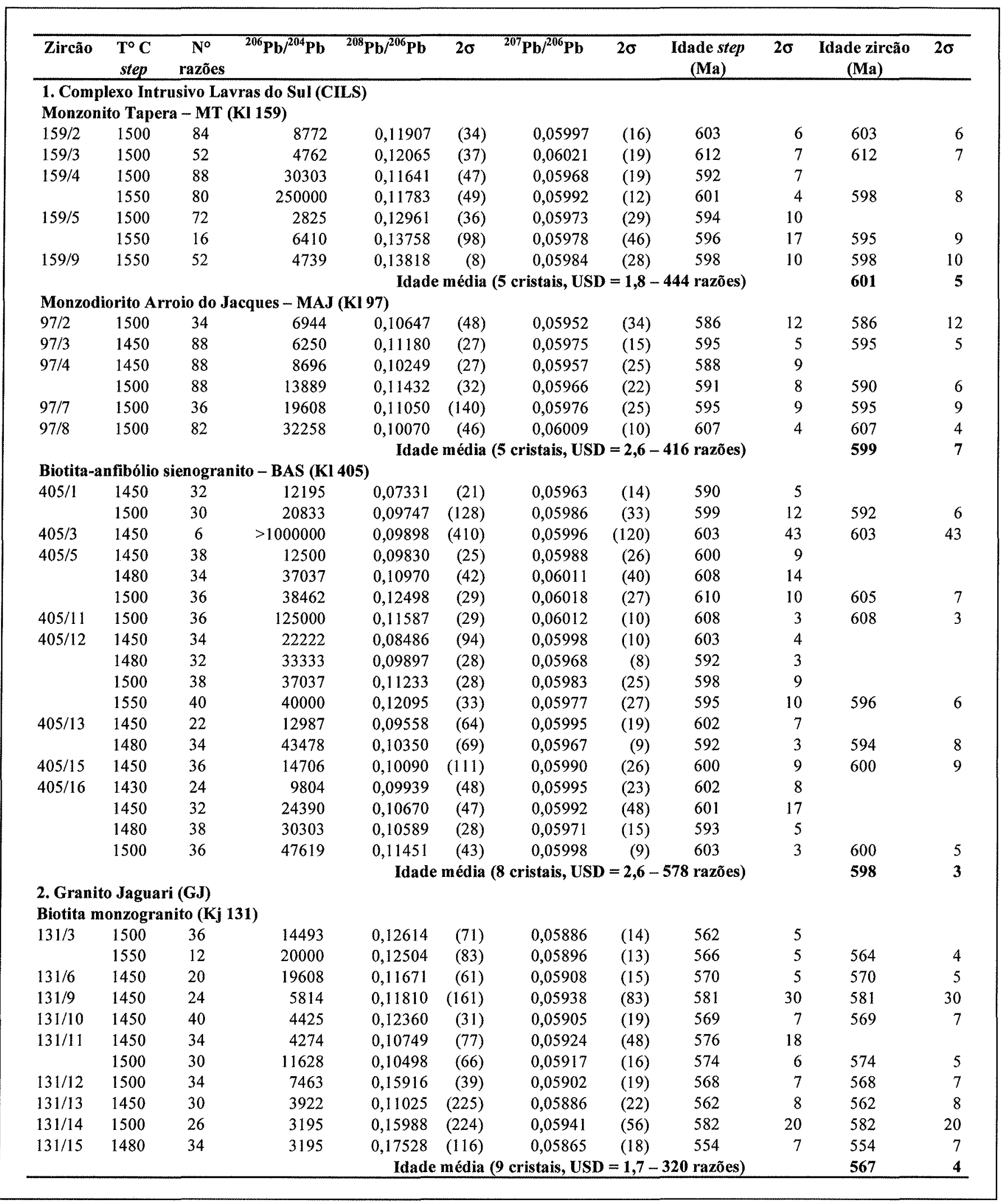

(Tab. 3), considerando spots concordantes em $\pm 83 \%$. No PG seriado, Remus et al. (2000) reconheceram outro tipo morfológico de zircão (prismas longos com zonação em setores), porém não identificaram variações significativas nas idades ${ }^{206} \mathrm{~Pb} /{ }^{238} \mathrm{U}$. Conclusão aparentemente contrária foi obtida por Leite $e t$ al.
(1998), em uma amostra do PG equigranular e mais evoluído (L5 - Fig. 2). Os cristais de zircão são similares, com núcleos euédricos e maciços, e bordas zonadas. Nove spots, do núcleo ( $\pm 90 \%$ concordantes), forneceram a idade média de $610 \pm 10$ Ma (2o), interpretada como de cristais herdados de evento de 


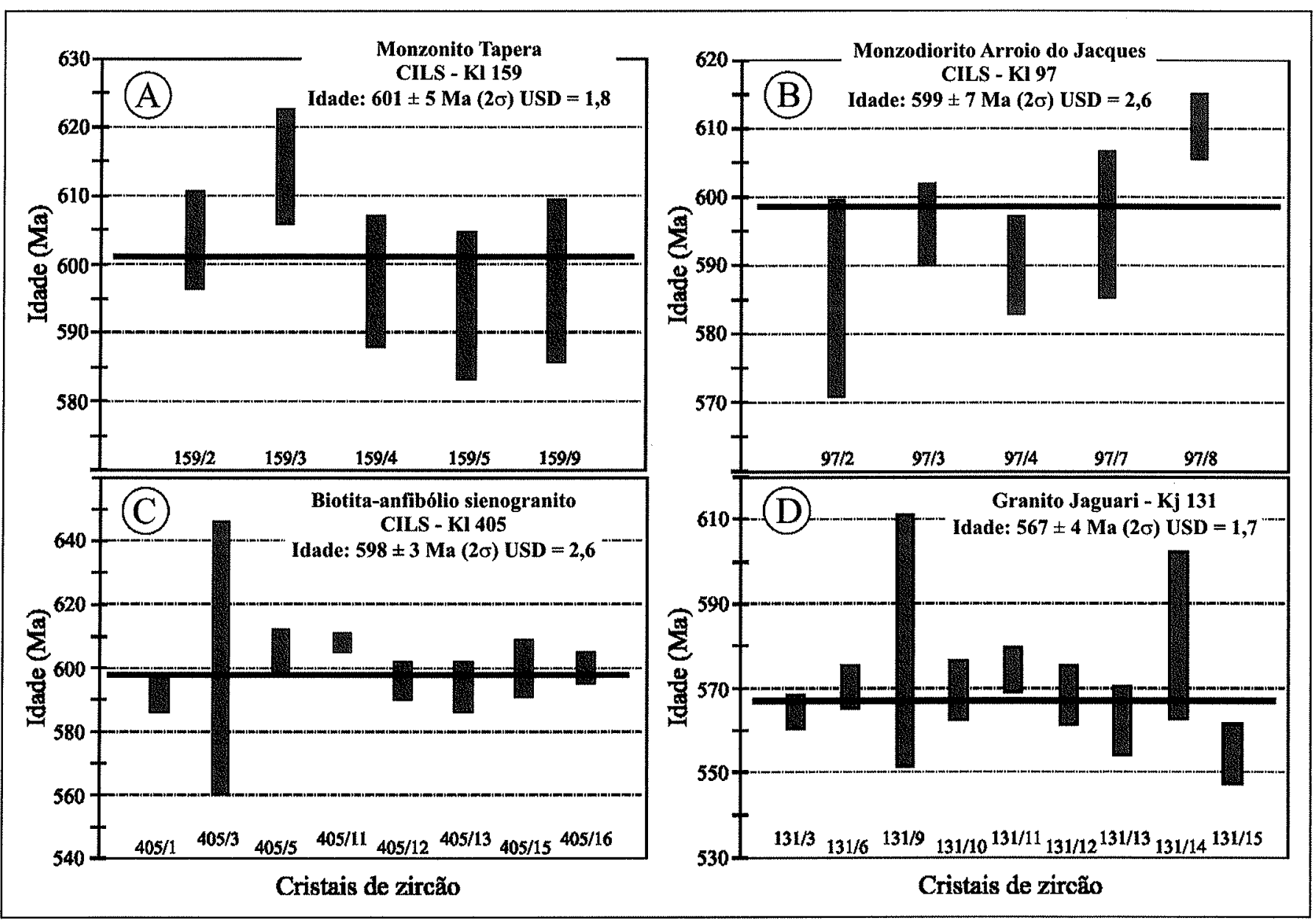

Figura 5 - Diagramas mostrando a média ponderada das idades ${ }^{207} \mathrm{~Pb}{ }^{206} \mathrm{~Pb}(2 \sigma)$ obtidas em cada cristal de zircão para: $A$ - Monzonito Tapera (Kl 159); B-Monzodiorito Arroio do Jacques (Kl 97); C-Biotita-anfibólio sienogranito, de afinidade alcalina (CILS - Kl 405); e D-Biotita monzogranito, granito Jaguari (Kj 131).

Tabela 3 - Quadro sintese das idades isotópicas (U-Pb e Pb-Pb) para granitóides do complexo intrusivo Lavras do Sul e do granito Jaguari, comparando dados da literatura e a interpretação efetuada neste trabalho.

\begin{tabular}{|c|c|c|c|c|}
\hline & \multicolumn{2}{|c|}{ Idades ${ }^{206} \mathrm{~Pb} /{ }^{238} \mathrm{U}(\mathrm{Ma})$} & \multicolumn{2}{|c|}{ Idades ${ }^{207} \mathrm{~Pb} /{ }^{206} \mathrm{~Pb}(\mathrm{Ma})$} \\
\hline & Literatura & Interpretação & Literatura & Neste trabalho \\
\hline \multicolumn{5}{|c|}{ 1. Complexo Intrusivo Lavras do Sul (CILS) - dois episódios de formação entre 606,0 e $583,2 \mathrm{Ma}$} \\
\hline \multicolumn{5}{|c|}{ Granitos alcalinos $\quad$ } \\
\hline Pertita granito seriado - (Lp4z) & $594 \pm 4^{1}$ & $\mathbf{5 8 6 , 0} \pm \mathbf{2 , 8}(\mathrm{MSWD}=1,6)$ & & \\
\hline Pertita granito equigranular - (L5) & $583 \pm 11$ & Cristais herdados: & & \\
\hline & $\begin{array}{l}\text { Cristais herdados } \\
\quad 610 \pm 10^{2}\end{array}$ & $\begin{array}{c}599,2 \pm 1,8 \text { (CILS) } \\
\mathrm{e}>615,5 \pm 4,9\end{array}$ & & \\
\hline Sienogranito - (K1 405) & & & & $598 \pm 3(\mathrm{USD}=2,6)$ \\
\hline \multicolumn{5}{|l|}{ Granitos do núcleo } \\
\hline Biotita granodiorito - $(\operatorname{Ln} 4 z)$ & $594 \pm 5^{1}$ & $\begin{array}{l}\mathbf{6 0 1 , 0} \pm \mathbf{2 , 0}(\mathrm{MSWD}=1,49) \\
\text { Reabertura do sistema U-Pb } \\
\text { em } 586-582\end{array}$ & & \\
\hline Monzonito Tapera - (KI 159) & & & & $601 \pm 5($ USD $=1,8)$ \\
\hline $\begin{array}{l}\text { Monzodiorito Arroio do Jacques } \\
\quad-(\mathrm{K} 197)\end{array}$ & & & & $\begin{array}{c}599 \pm 7(\text { USD }=2,6) \\
\text { ou } 593 \pm 4(\text { USD }=0,9) \\
\text { Cristal herdado: } 607 \pm 4\end{array}$ \\
\hline \multicolumn{5}{|c|}{ 2. Granito Jaguari (GJ) - evento de natureza alcalina mais jovem } \\
\hline Biotita monzogranito - $(\mathrm{Kj} \mathrm{l} 31)$ & & & $565 \pm 55^{3}$ & $567 \pm 4($ USD $=1,7)$ \\
\hline
\end{tabular}


cristalização precoce do corpo granítico. A idade de cristalização do PG, segundo Leite et al. (1983), de $583 \pm 11 \mathrm{Ma}(2 \sigma)$ foi obtida para dez spots $( \pm 90 \%$ concordantes) da borda dos grãos. Em face da divergência e da dispersão das idades ${ }^{206} \mathrm{~Pb} /{ }^{238} \mathrm{U}$ em diagramas concórdia (Fig. 8 de Leite et al. 1998; Figs. 9-10 de Remus et al. 2000), efetuou-se a revisão estatística das idades com $\pm 90 \%$ de concordância (resultados a $2 \sigma$ ). Os diagramas de probabilidade relativa sobrepostos a histogramas, e a média ponderada das idades foram obtidos com o ISOPLOT/EX (Ludwig 2001), e a probabilidade calculada segundo Sircombe (2004). Nas três amostras, não existe relação clara entre os teores de U e Th dos zircões e a idade ${ }^{206} \mathrm{~Pb} /{ }^{238} \mathrm{U}$, porém o crescimento de $\mathrm{Th}$ acompanha a diferenciação no $\mathrm{PG}$ (seriado para equigranular, Fig. 6A). Os valores de Th/U, embora algo dispersos, mostram certa constância em amostras do PG $(\sim 0,3$ e 0,4$)$, enquanto no $\mathrm{BG}$, a dispersão é maior, e os valores crescem com o decréscimo das idades ${ }^{206} \mathrm{~Pb} /{ }^{238} \mathrm{U}$ (Fig. 6B). Isto pode ser um indicativo do efeito de evento hidrotermal superposto, o que é significativo, uma vez que os bolsões de BG porfirítico estão na porção central do corpo, próximo às ocorrências de $\mathrm{Au}-\mathrm{Cu}$.

BIOTITA GRANODIORITO PORFIRÍTICO Na amostra de BG (Ln4z), dos 36 spots considerados por Remus et al. (2000), 34 são mais concordantes que $\pm 90 \%$. As idades ${ }^{206} \mathrm{~Pb} /{ }^{238} \mathrm{U}$ exibem distribuição multimodal (Fig. 7A), com o principal intervalo de freqüência ao redor de 601-603 Ma, o qual é mantido em spots mais concordantes $(95 \%$ e $98 \%)$. A idade ${ }^{206} \mathrm{~Pb} /{ }^{238} \mathrm{U}$ média, de 593,4 $\pm 2,9 \mathrm{Ma}(\mathrm{MSWD}=4,58)$, não corresponde ao máximo na freqüência. As idades mais jovens são mais dispersas, com pequeno alto em 586-582 Ma. Estas podem ser atribuídas ao efeito de evento hidrotermal tardio, já que são mais discordantes. A idade Ar/Ar* de $590 \pm 4 \mathrm{Ma}$, para flogopita do minete (Gastal et al. em preparação), confirma que os granitos do núcleo, em especial, os termos híbridos foram formados em evento anterior. Assim, calculou-se a idade ${ }^{206} \mathrm{~Pb} /{ }^{238} \mathrm{U}$ média para 18 spots com idades acima de $594 \mathrm{Ma}$, que é de $601 \pm 2$ Ma (MSWD $=1,49)$. Excluindo os dois spots mais antigos $(z$ $610 \mathrm{Ma}$ ), e mais dispersos (Fig. 7A), obtém-se idade similar de $599,5 \pm 2,2 \mathrm{Ma}(\mathrm{MSWD}=0,35)$. A idade de $601 \pm 2 \mathrm{Ma}$ foi interpretada como a melhor estimativa para a cristalização do $\mathrm{BG}$. Esta é consistente com as idades ${ }^{207} \mathrm{~Pb} /{ }^{206} \mathrm{~Pb}$ do MT-MAJ (601士 $5 \mathrm{Ma}$ e $599 \pm 7 \mathrm{Ma}$ ), corroborando ser este o principal período de atividade ígnea no CILS.

PERTITA GRANITO No PG, as idades ${ }^{206} \mathrm{~Pb} / 238 \mathrm{U}$ das duas amostras (L5 e Lp4z) foram tratadas em conjunto, uma vez que representam variedades da mesma fácies petrográfica. No PG seriado (Lp4z), dos 27 spots considerados por Remus et al. (2000), 24 são mais concordantes que $\pm 90 \%$. No PG equigranular (L5), descartou-se o spot com idade mais jovem e discrepante $\left(\mathrm{n}^{\circ} 15\right.$, Leite et al. 1998). As idades ${ }^{206} \mathrm{~Pb} /{ }^{238} \mathrm{U}$, em conjunto (42 spots), exibem distribuição multimodal típica (Fig. 7B), com dois intervalos de freqüência, 603-597 Ma e 587-585 Ma. Tal comportamento, similar ao observado em corpos graníticos multi-intrusivos (Fanning et al. 2003), faz com que a idade média, de 594,4 $\pm 3,3 \mathrm{Ma}(\mathrm{MSWD}=6,30)$, corresponda a um baixo na freqüência das idades ${ }^{206} \mathrm{~Pb} /{ }^{238} \mathrm{U}$. O máximo na curva de probabilidade e a bimodalidade das idades ${ }^{206} \mathrm{~Pb} /{ }^{238} \mathrm{U}$ são mantidos nos spots $95 \%$ concordantes, e naqueles $98 \%$ concordantes predominam as idades mais jovens, com um pico em 588-586 Ma. Os valores extremos das idades ( $\sim 567 \mathrm{Ma}$ e $610-623 \mathrm{Ma})$ são de spots do PG equigranular (L5). Nesta amostra, a discrepância estrutural das idades (núcleo e borda) pode estar indicando diferentes eventos de cristalização, como já referido. Entretanto, é apenas nessa amostra que as idades mais antigas ( $\geq 609 \mathrm{Ma}$ ) estão bem caracterizadas, definindo um grupo a parte (Fig. 7B).
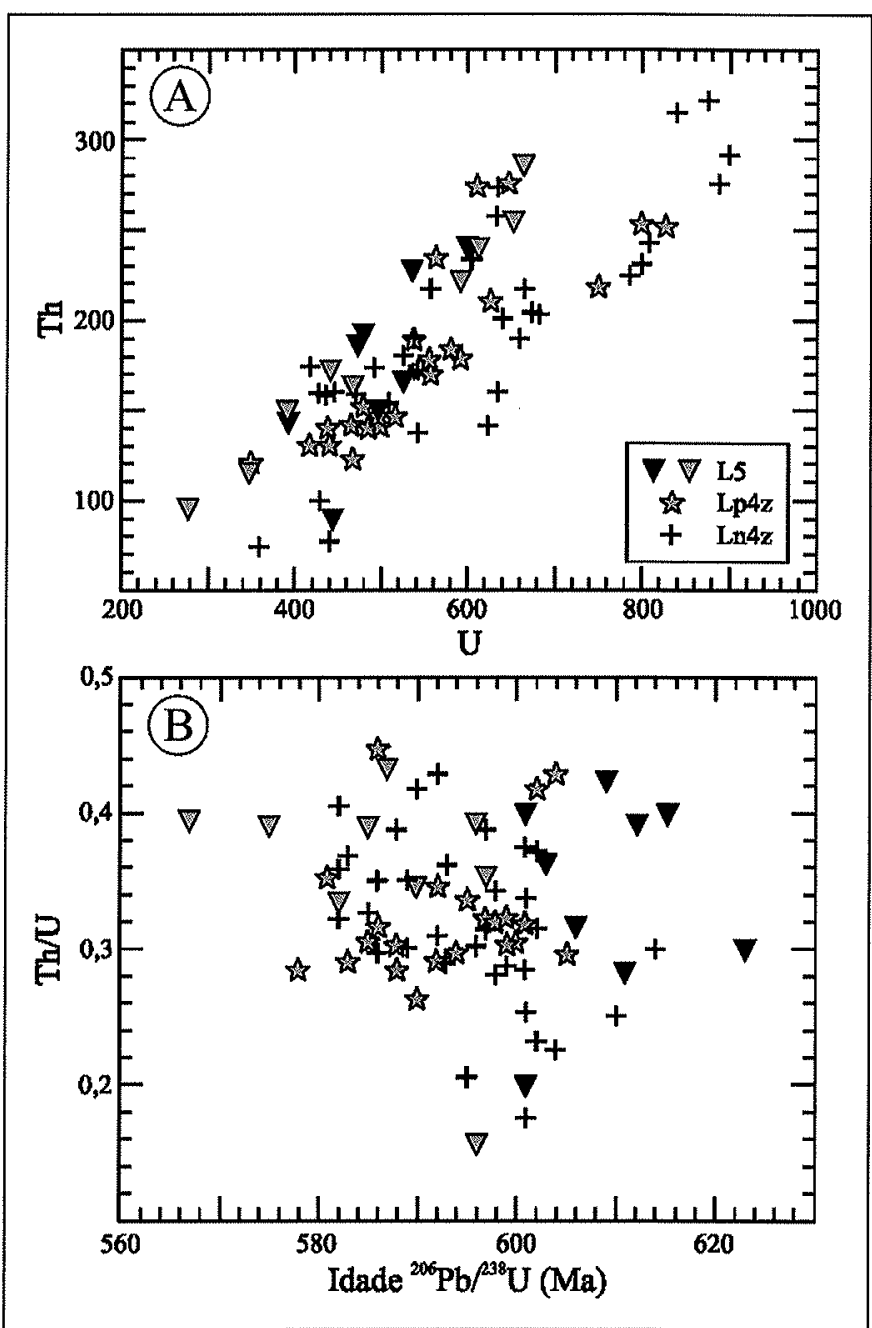

Figura 6 - Composição e idades ${ }^{206} \mathrm{~Pb}{ }^{238} U$ ( $\pm 90 \%$ concordantes), obtidas por SHRIMP, em zircões de três amostras de granitos do complexo intrusivo (Leite et al. 1998 e Remus et al. 2000). A-Diagrama Th vs. U (ppm); B-Diagrama Th/U vs. idade ${ }^{206} \mathrm{~Pb}^{238} \mathrm{U}$. L5 - pertita granito equigranular (preto para núcleo euédrico e cinza borda subédrica), Lp $4 z$ - pertita granito seriado e Ln $4 z$ - biotita granodiorito porfiritico.

Dada a localização da amostra L5 na borda do CILS (Fig. 2), é bem provável que os núcleos de zircão com idades superiores a ca. $609 \mathrm{Ma}$ estejam refletindo cristais herdados dos granitóides encaixantes (Complexo Cambaí). Excluindo estas idades, o número reduzido de spots dificulta a análise estatística nessa amostra. As idades ${ }^{206} \mathrm{~Pb} /{ }^{238} \mathrm{U}$ no $\mathrm{PG}$ seriado (Lp4z), tratadas separadamente, também exibem distribuição multimodal, com os máximos em 599-597 Ma e 587-585 Ma (Fig. 7C). Igualmente, as idades ao redor de $586 \mathrm{Ma}$ são mais concordantes, porém, neste caso, a dispersão é maior. Ao contrário da amostra do $\mathrm{BG}$, a variação nas idades ${ }^{206} \mathrm{~Pb} /{ }^{238} \mathrm{U}$ de acordo com o grau de concordância poderia ter um significado geológico importante. Em metagranitóides, Connelly (2000) relaciona o grau de concordância de idades U-Pb e a preservação de zircões primários, uma vez que aqueles mais afetados por eventos pós-cristalização comumente são discordantes. Embora em contexto geológico distinto, este tipo de variação nas amostras de $\mathrm{PG}$ poderia ser um argumento a favor da proposição de que as idades ao redor de 603-597 Ma refletem cristais herdados de fácies precoces do CILS, e as mais jovens a cristalização do PG.

Em função da bimodalidade, os spots das duas amostras de 


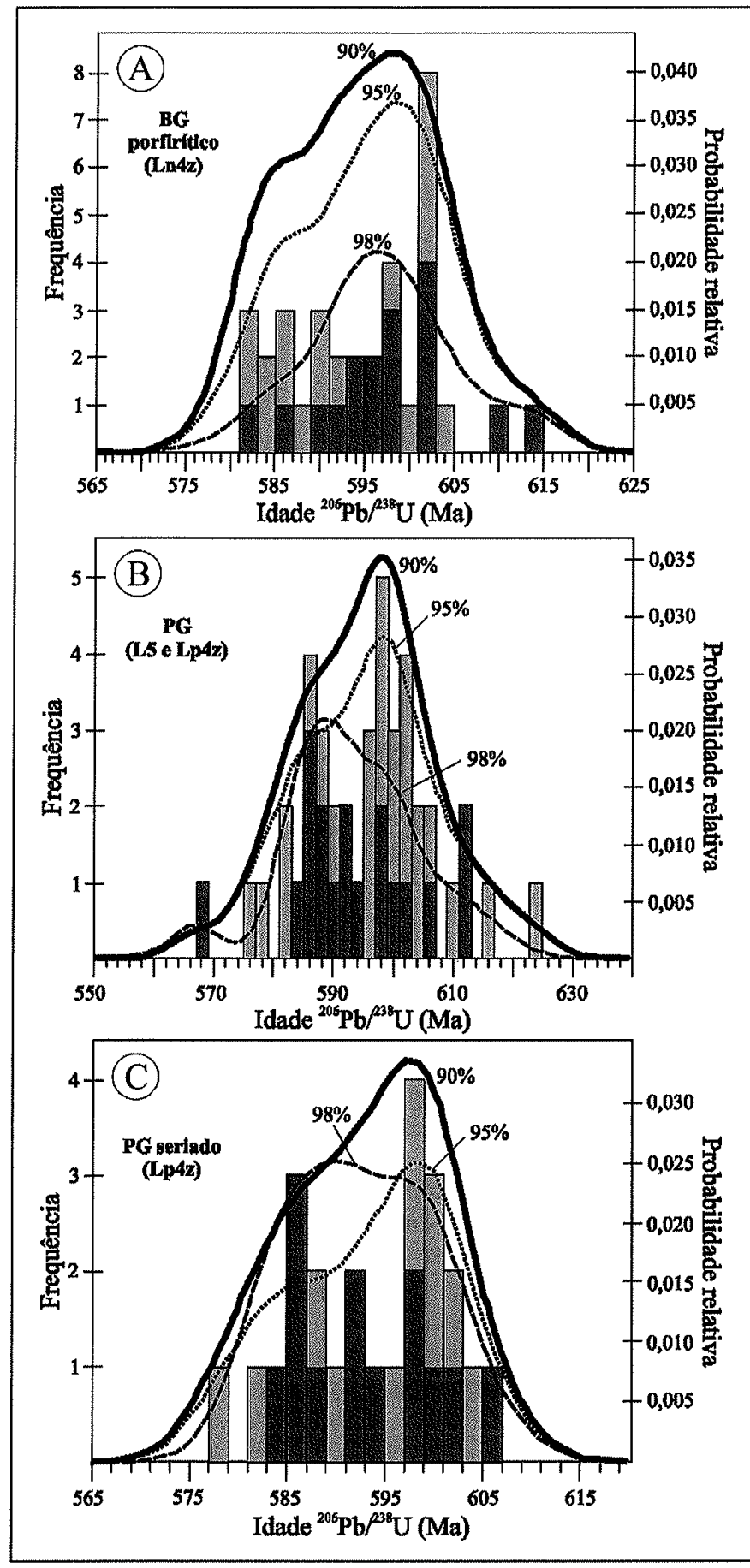

Figura 7 - Diagramas de probabilidade relativa sobrepostos a histogramas das idades ${ }^{206} \mathrm{~Pb}^{238} \mathrm{U}( \pm 90 \%$ concordantes): $\mathrm{A}$. Biotita granodiorito porfiritico (Ln4z-Remus et al. 2000); $B$ - Pertita granito (equigranular: L5 - Leite et al. 1998, e seriado: Lp4z-Remus et al. 2000); e C-Pertita granito seriado ( $\mathrm{Lp} 4 z$ - Remus et al. 2000). São mostradas as curvas de probabilidade para spots $95 \%$ (pontilhada) e 98\% (tracejada) concordantes. Cinza claro e escuro marcam, respectivamente, spots $90 \%$ e 98\% concordantes. As idades médias ${ }^{206} \mathrm{~Pb}^{238} \mathrm{U}$, obtidas pelos autores, para cada amostra constam na tabela 3.

PG com idades superiores e inferiores a 594 Ma foram tratados separadamente, com o cálculo das respectivas idades médias. Para os primeiros, obteve-se a idade de $601,3 \pm 2,7 \mathrm{Ma}$ $(\mathrm{MSWD}=2,40-25$ spots $)$, ou de 599,2 $\pm 1,8 \mathrm{Ma}(\mathrm{MSWD}=$ 0,66 - 18 spots) quando as idades superiores a 609 Ma são ex- cluídas. A idade de 599,2 $\pm 1,8 \mathrm{Ma}$ melhor expressa o máximo na freqüência (Fig. 7B), e é convergente com as idades do BG e MT-MAJ. Deste modo, parece lógica a interpretação de que esta idade reflete cristais herdados de evento de cristalização precoce do CILS. Para 17 spots mais jovens, obteve-se a idade média ${ }^{206} \mathrm{~Pb} /{ }^{238} \mathrm{U}$ de $584,8 \pm 3,5 \mathrm{Ma}(\mathrm{MSWD}=2,69)$, ou de $586,0 \pm 2,8$ $\mathrm{Ma}(\mathrm{MSWD}=1,6)$ quando se exclui o spot com idade inferior a $570 \mathrm{Ma}$. Considerando apenas 12 spots da amostra Lp5z, obtém-se idade similar de $587,2 \pm 3,1 \mathrm{Ma}(\mathrm{MSWD}=1,4)$. A idade de $586,0 \pm 2,8 \mathrm{Ma}$ melhor expressa o máximo na freqüência dos spots mais jovens (Fig. 7B-C), sendo interpretada como a melhor estimativa para a cristalização do PG.

\section{SISTEMA VULCANO-PLUTÔNICO DE SUBSIDÊNCIA}

Conceitos A literatura que trata de tipos e processos de formação de caldeiras, associadas a vulcanismo dominantemente intermediário a ácido, é rica e extensa (Smith \& Bailey 1968 , Marti et al. 1994, Lipman 1997, Cole et al. 2004, etc.). Lipman (1984) e Johnson et al. (2002), não obstante, realçaram a importância da interface subvulcânica/plutônica que, apesar da complexidade e multiplicidade de processos, preserva os eventos magmáticos facilitando o estudo das raízes de estruturas vulcânicas e do topo de câmaras epizonais. Tais rochas representam níveis estruturais progressivamente mais profundos de um mesmo sistema de alimentação de magma, ativo em um dado período, que foi denominado de sistema vulcano-plutônico de subsidência (Shannon 1988, in Johnson et al. 2002). As rochas intrusivas, nestes sistemas, incluem composições variadas (máficas e félsicas) com posicionamentos diversos (cone-sheets, diques anelares ou radiais, intrusões centradas, etc.). Nesse caso, a estratigrafia magmática deve ser inferida principalmente pelas feições de campo e petrografia, uma vez que as diferenças no tempo de posicionamento e cristalização ( $<1-2 \mathrm{Ma})$ estão, na maioria das vezes, dentro das incertezas analíticas dos métodos geocronológicos. Além disso, em face da dinâmica desses sistemas, é possível estabelecer apenas a cronologia relativa dos eventos e não a profundidade absoluta do posicionamento das intrusões, como lembram Johnson et al. (2002). Os três estágios principais sintetizando a seqüência de eventos nos sistemas vulcano-plutônicos, propostos por estes autores, podem ser resumidos como segue:

(1) Fraturamento da crosta acima do corpo de magma sob pressão, resultando em fraturas cônicas e colocação de intrusões tipo cone-sheets. Estas incluem composições menos diferenciadas, e representam o estágio inicial de estabilização da câmara magmática e da formação dos principais condutos alimentadores do vulcanismo associado.

(2) A subsequiente evasão de magma, associada a desvolatilização, reduz a pressão na câmara e facilita o colapso do teto ao longo de falhas verticais, que normalmente são condutos para líquidos mais félsicos que podem formar diques anelares.

(3) Ressurgência da câmara magmática expressa, nos níveis mais superficiais, pelos domos estruturais ou ressurgentes (Lipman 1984, 1997, Saunders 2005), ou associada ao desenvolvimento de lacólitos (lacocalderas, Henry \& Price 1989). A continuidade da evolução e da ressurgência da câmara magmática pode simplesmente conduzir à formação de intrusões agregadas (nested intrusions) e cogenéticas com as vulcânicas. Estas estão comumente posicionadas nos locais de maior subsidência, e destroem as evidências da história prévia de parte do centro vulcano-plutônico (Lipman 1997, Johnson et al. 2002).

Em cada sistema particular, essa seqüência de eventos pode 
ser repetida inúmeras vezes, resultando em estruturas variadas dependendo do regime tectônico, da profundidade da câmara e do volume, composição e propriedades físicas dos magmas envolvidos.

Complexo Intrusivo Lavras do Sul A correlação entre grande parte das intrusivas do CILS e traquiandesitos e subvulcânicas da Formação Hilário tem sido assumida com base nas relações de campo e afinidade geoquímica (Lima 1995, Lima \& Nardi 1998). Intercalações de vulcanoclásticas, no pacote de efusivas, registram a importância da atividade vulcânica explosiva normalmente associada à subsidência de caldeiras. A formação e posicionamento das unidades do CILS estão relacionados a um mesmo conjunto de processos, como sugerem a continuidade espacial (Fig. 2), o padrão singular de lineamentos magnéticos (Fig. 4F) e a contemporaneidade de grande parte das intrusivas, revelada pelas idades ${ }^{206} \mathrm{~Pb} /{ }^{238} \mathrm{U}$ e ${ }^{207} \mathrm{~Pb} /{ }^{206} \mathrm{~Pb}$ (Tab. 3). Estas feições permitem inferir que o CILS é a contraparte em profundidade de um sistema vulcano-plutônico de subsidência. O limite nordeste-leste-sudeste deste, contra a seqüência vulcânica e a Formação Maricá, é marcado por contrastes gravimétricos e magnéticos importantes (Fig. 4). Tal limite pode ser atribuído à borda de um sistema de subsidência, porém dificilmente corresponderia à estrutura de uma única caldeira. $\mathrm{O}$ monzonito Tapera (MT), com forma de meia lua, é truncado a sul pelo corpo granítico que é grosseiramente circular (Fig. 2). Esta disposição, em planta, sugere que os dois (MT e corpo granítico) representam intrusões agregadas que evoluíram de norte para sul. As relações de campo corroboram esta idéia, porém as idades ${ }^{206} \mathrm{~Pb} /{ }^{238} \mathrm{U}$ e ${ }^{207} \mathrm{~Pb} / 206 \mathrm{~Pb}$, embora consistentes, não são conclusivas (Tab. 3 ).

ESTRUTURAÇÃO A separação entre os setores norte e sul do CILS é realçada por diferenças na composição dos diques (Fig. 2). No setor norte, a presença de diques similares às lavas Hilário reflete a continuidade da atividade vulcânica durante e após a colocação do MT, o que não está registrado no setor sul (corpo granítico e MAJ). Desta forma, o MT seria uma intrusão formada durante a estabilização da câmara alimentadora do vulcanismo correlato, e os enxames de diques, que marcam o contato norte, representariam restos de cone-sheets percussores desse vulcanismo. A contemporaneidade entre MT e MAJ é sugerida pelas relações de campo. Porém, o MAJ está disposto ao redor do corpo granítico, e é secionado pela fácies porfirítica do MT e pelos granitos alcalinos, enquanto o corpo granítico não é secionado pela primeira. Estas relações tornam mais complexa a formação e posicionamento do MAJ. A forma circular, bem como a presença de raizes alimentadoras no centro do corpo granítico sugere que este seja um pluton ressurgente posicionado após o colapso de uma caldeira. Sua formação envolveu aparentemente a mudança na afinidade geoquímica dos magmas parentais (álcali-cálcico para alcalino). Os granitos exibem distribuição concêntrica e zonalidade reversa (Fig. 2), referendada pelos dados magnéticos e gravimétricos (Fig. 4). As principais raízes alimentadoras estão sob os granitos do núcleo (BG e $\mathrm{ABM}$ ), ao redor dos quais foram posicionados os termos alcalinos (BAS e PG), que podem estar vinculados a diques máficos e anelares em profundidade. No MAJ, os dioritos com ortopiroxênio estão no sudeste do corpo, coincidindo com anomalia magnética bipolar de grande amplitude do sinal analítico (Fig. 4D). Isto pode ser atribuído à ocorrência de rochas básicas em subsuperficie. Então, a formação do MAJ foi associada ao final da evolução do MT, com a entrada de líquidos básicos, e o seu posicionamento teria sido, em parte, condicionado pela ressurgência do pluton granítico.
EPISÓDIOS MAGMÁTICOS As idades ${ }^{206} \mathrm{~Pb} /{ }^{238} \mathrm{U}$ e ${ }^{207} \mathrm{~Pb} /$ ${ }^{206} \mathrm{~Pb}$ sugerem que o CILS foi formado em, pelo menos, dois eventos entre 606,0 e $583,2 \mathrm{Ma}$ (Tab. 3, Figs. 5 e 7). O primeiro (606-595 Ma), bem caracterizado pelos dois métodos geocronológicos, representa o principal episódio formador do CILS, responsável pelo posicionamento das intrusivas de natureza shoshonítica, como granitos do núcleo, MT e MAJ. As idades ${ }^{207} \mathrm{~Pb} /{ }^{206} \mathrm{~Pb}$ são consistentes com a contemporaneidade na cristalização do MAJ e MT, porém o possível registro de evento mais jovem no primeiro $(\sim 593 \mathrm{Ma})$ pode ser atribuído ao seu posicionamento particular. A granitogênese alcalina parece ter ocorrido em mais de um episódio, como registram as idades ${ }^{206} \mathrm{~Pb} /{ }^{238} \mathrm{U}$ do $\mathrm{PG}$ e ${ }^{207} \mathrm{~Pb} /{ }^{206} \mathrm{~Pb}$ do BAS, respectivamente $586,0 \pm$ $2,8 \mathrm{Ma}$ e $598 \pm 3 \mathrm{Ma}$ (Tab. 3). No último, as idades ${ }^{207} \mathrm{~Pb} /{ }^{206} \mathrm{~Pb}$ de steps não são conclusivas quanto ao registro de um evento mais jovem (Tab. 2), de modo que o BAS representa episódio de natureza alcalina, cerca de 12 Ma mais antigo que o PG e, em parte, contemporâneo à formação das demais unidades do CILS. Diferenças de idade desta ordem implicariam em contrastes térmicos entre os granitos alcalinos (BAS e PG), o que não é observado. A alternativa seria de que a região tenha permanecido aquecida durante este período, e a colocação e formação de parte do pluton granítico tenham ocorrido em incrementos. A distribuição espacial e os lineamentos magnéticos dos granitos alcalinos são consistentes com a idéia de que represente diques anelares múltiplos (Figs. 2 e 4), o que poderia justificar em parte as diferenças de idade. De acordo com Saunders (2005), tais diques resultam de sucessivas intrusões ao longo de falhas semicirculares (circumferential faults), formadas ou não durante os períodos de subsidência. São também responsáveis pelos episódios finais de ressurgência da câmara magmática que, nesse caso, é extremamente prolongada.

Idades mais jovens, ${ }^{206} \mathrm{~Pb} /{ }^{238} \mathrm{U}$ de $580,2 \pm 1,8 \mathrm{Ma}(2 \sigma) \mathrm{e} \mathrm{Rb}-$ $\mathrm{Sr}$ (minerais) de $582 \pm 6,3 \mathrm{Ma}(1 \sigma)$, foram obtidas em granitos hidrotermalizados do CILS associados às mineralizações de Au$\mathrm{Cu}$ (Bongiolo et al. 2003). Desta forma, a evolução do CILS estendeu-se até próximo a $580 \mathrm{Ma}$, o que explicaria a dispersão nas idades ${ }^{206} \mathrm{~Pb} /{ }^{238} \mathrm{U}$ (Fig. 7). Isto permite propor que a idade de ca. $586 \mathrm{Ma}$, registrada no PG, se deva a eventos hidrotermais tardios cujos efeitos teriam sido diferenciados para cada intrusão (cristalização/recristalização de zircão ou reabertura do sistema isotópico). De acordo com esta alternativa, a idade de cristalização do PG estaria ao redor de 599-598 Ma (Fig. 7B-C), corroborando a idéia de que a formação do CILS ocorreu em um curto período $(<11 \mathrm{Ma})$. Esta alternativa compatibiliza todos os dados $\mathrm{U}-\mathrm{Pb}$ e $\mathrm{Pb}-\mathrm{Pb}$ disponíveis. Igualmente, é consistente com a idade Ar/Ar*de $590 \mathrm{Ma}$ dos minetes (Gastal et al. em preparação), que constitui um limite inferior para a formação dos granitos do núcleo do CILS. Contudo, não se pode descartar a possibilidade de que os minetes estejam associados aos granitos alcalinos, o que seria um argumento contrário a essa alternativa. Além disso, a resposta diversificada do sistema isotópico U-Pb nos zircões pode ser atribuída à natureza multi-intrusiva do corpo granítico (Fanning et al. 2003, Coleman et al. 2004), e não exclusivamente a eventos hidrotermais. Estudos detalhados de zircões, incluindo análises químicas e catodoluminescência, são necessários para uma decisão mais criteriosa entre as duas alternativas. Optou-se pela primeira, que prevê a formação do CILS em um intervalo inferior a $22,8 \mathrm{Ma}$, estando o principal evento ígneo ao redor de 603-597 Ma.

CONSIDERAÇÕES FINAIS A integração de dados geológicos, geofísicos e geocronológicos das intrusivas que compõem o CILS permite caracterizá-lo como um sistema vulcano-plutônico de subsidência, análogo a exemplos clássicos. As linhas gerais da estruturação deste complexo intrusivo e o vínculo com as 
vulcânicas da Formação Hilário parece claro, porém os detalhes de sua evolução merecem estudos futuros. As idades ${ }^{206} \mathrm{~Pb} /{ }^{238} \mathrm{Ue}$ ${ }^{207} \mathrm{~Pb} /{ }^{206} \mathrm{~Pb}$ das diferentes intrusivas são comparáveis, e revelam que o principal período de formação do CILS ocorreu ao redor de 603-597 Ma. Indicam a coexistência entre magmas parentais de natureza diversa, como também sugerido pela evolução na composição dos diques. A granitogênese alcalina no CILS parece ter se prolongado até ca. $586 \mathrm{Ma}$, embora os dados não sejam de todo conclusivos. A idade ${ }^{207} \mathrm{~Pb} / 206 \mathrm{~Pb}$ de $567 \pm 4 \mathrm{Ma}$ para o Granito Jaguari confirma que este representa um evento mais novo e distinto daquele que originou os granitos de mesma afinidade no CILS, referendando as relações de campo.
Agradecimentos Este trabalho foi financiado com os auxílios de pesquisa FAPERGS no 98/0662-1, 00/2366-3, 00/1366-8 e 03/0321-3, e PRONEX/CPGq - IGEO-UFRGS. Somos gratos aos revisores anônimos, e à CPRM - Serviço Geológico do Brasil que nos forneceu os dados aeromagnetométricos da região. Agradecemos a ajuda e assistência conferida pelo staff dos laboratórios de Geologia Isotópica/CG-UFPA - Pará-Iso e de Geofísica Aplicada - DEGEOL/UFPR. Participaram em diferentes etapas deste trabalho, os colegas bolsistas de iniciação científica Cristiano F. Fialho (PIBIC-CNPq, UFPR), Gustavo A. Fernandes (FAPERGS n ${ }^{\circ}$ 00/51404.4), e João Felipe H. Appollo (PIBIC-CNPq, UFRGS).

\section{Referências}

Babinski, M., Chemale Jr., F., Hartmann, L. A., VanSchmus, W. R., Silva, L. C. da., 1996. Juvenile accretion at 750-700 Ma in southern Brazil. Geology, 24(5): 439-442.

Bongiolo, E.M., Mexias, A.S., Santos, J.O.S., Hartmann, L.A., Conceição, R.V., Gomes, M.E.B., Formoso, M.L.L. 2003. Geocronologia do hidrotermalismo versus magmatismo no Distrito Aurífero de Lavras do Sul. In: SBG, Encontro Estratigrafia do Rio Grande do Sul: Escudo e Bacias, 1, Anais, p. 83-88.

Cole, J.W., Milner, D.M., Spinks, K.D. 2004. Calderas and caldera structures: a review. Earth Sci. Rev., 69(1-2): 1-26.

Coleman, D.S., Gray, W., Glazner, A.F. 2004. Rethinking the emplacement and evolution of zoned plutons: Geochronologic evidence for incremental assembly of the Tuolumme Intrusive Series, California. Geology, 32:433-436.

Connelly, J. N. 2000. Degree of preservation of igneous zonation in zircon as a signpost for concordancy in $\mathrm{U} / \mathrm{Pb}$ geochronology. Chem. Geol., 172: 25-39.

Costa, A.F.U. 1997. Teste e Modelagem Geofisica da Estruturação das Associações Litotectônicas Pré-Cambrianas no Escudo Sulriograndense. Tese de Doutoramento em Geociências, Instituto de Geociências, Universidade Federal do Rio Grande do Sul, 291p.

CRM, 1998. Diagnóstico do Potencial Mineral do Município de Lavras do Sul, RS (CD-room, inédito).

De Ros, L.F. \& Fernandes, L.A.D. 1981 . Rochas charnoquíticas no Escudo Sul-riograndense. Acta Geol. Leop., 5: 25-44.

Fanning, M.C., Pankhurst, R.J., Rapela, C.W., Hervé, F. 2003. Unravelling complex SHRIMP U-Pb zircon ages for Paleozoic and Mesozoic magmatic rocks: fact or artefact. In: IRD-CBMM, South Amer. Symp. Isotope Geol., 4, Short Papers, p. 549-552.

Gastal, M.C.P. 1998. Suite Intrusiva Saibro, RS: Avaliação de um Modelo Petrológico. Tese de Doutoramento em Geociências, Instituto de Geociências, Universidade Federal do Rio Grande do Sul, $365 \mathrm{p}$.

Gastal, M.C.P. \& Nardi, L.V.S. 1992. Petrogênese e evolução do Granito Jaguari: um típico representante metaluminoso da Suíte Intrusiva Alcalina Saibro, RS. Geochim. Brasil., 6(2): 169-189.

Gastal, M. C. P. \& Lafon, J. M., 1998. Gênese e evolução dos granitóides metaluminosos de afinidade alcalina da porção oeste

do Escudo Sul-riograndense: geoquímica e isótopos de $\mathrm{Rb}-\mathrm{Sr}$ e $\mathrm{Pb}-\mathrm{Pb}$. Rev. Bras. Geoc. 28(1), 11-28.
Gastal, M. C. P. \& Lafon, J. M., 2006. Reinterpretação do Complexo Intrusivo Lavras do Sul, RS, de acordo com os sistemas

vulcano-plutônicos de subsidência. Parte 2: química mineral, geoquímica e isótopos de Pb-Sr-Nd. Rev. Bras. Geoc., 36 (1): 121-142.

Gastal, M.C., Fernandes, G.A., Ferreira, F.J.F., Frizzo, R.G. 2006. Zonalidade reversa dos granitos do Complexo Intrusiv

Lavras do Sul, RS: Petrografia, susceptibilidade magnética e óxidos de Fe-Ti. Rev. Bras. Geoc., 36 (1): 106-120.

Gaudette, H.E., Lafon, J.M., Macambira, M.J.B., Moura, C.A.V., Scheller, T., 1998. Comparison of single filament $\mathrm{Pb}$ evaporation/ionization zircon ages with conventional U-Pb results: examples from the Precambrian of Brazil. J. South Amer. Earth Sci., 11(4):351-363.

GEOSOFT. 2001. Magmap TM (FFT-2D) frequency domain processing of potencial field data. User guide. Geosoft Inc., Toronto, $54 \mathrm{p}$.

Hartmann, L.A., Porcher, C.C., Remus, M.V.D. 2000. Evolução das rochas metamórficas do Rio Grande do Sul. In: Holz, M. \& De Ros, L.F. (eds.) Geologia do Rio Grande do Sul, EDUFRGS, p. 79-118.

Henry, C.D. \& Price, J.G. 1989. The Christmas Mountains caldera complex, Trans-Pecos, Texas. Geology and development of a laccocaldera. Bull. Volcanol., 52(2):97-112.

Jackson, V.N., Ramos, V.A, Terry, S.A, Zuzek, A B. 1973. Projeto Aerogeofisico Camaquã, Estado do Rio Grande do Sul. Porto Alegre, Texas Instruments, DNPM/CPRM/CENEN, 208p.(inédito).

Johnson, S.E., Schmidt, K.L., Tate, M.C. 2002. Ring complexes in the Peninsular Ranges Batholith, Mexico and the USA: magma plumbing systems in the middle and upper crust. Lithos, 61:187-208.

Kober, B., 1986. Whole-grain evaporation for ${ }^{207} \mathrm{~Pb} / 206 \mathrm{~Pb}$-age-investigations on single zircons using a double-filament thermal ion source. Contrib. Mineral. Petrol., 93:482-490.

Kober, B., 1987. Single-zircon evaporation combined with $\mathrm{Pb}^{+}$emitter bedding for ${ }^{207} \mathrm{~Pb} /{ }^{206} \mathrm{~Pb}$-age investigations using thermal ion mass spectrometry, and implications to zirconology. Contrib. Mineral. Petrol., 96:63-71.

Leite, J.A.D. 1997. A origem dos harzburgitos da seqüencia Mantiqueiras e implicações tectônicas para o desenvolvimento do Neoproterozóico. Tese de Doutoramento em Geociências, Instituto de Geociências, Universidade Federal do Rio Grande do Sul, 243p.

Leite, J.A.D., Hartmann, L.A., McNaughton, N.J., Chemale Jr. 1998. SHRIMP U/Pb zircon geochronology of Neoproterozoic 
juvenile and crustal-reworked terranes in southernmost Brazil. Intern. Geol. Rev, 40:683-705.

Lima, E.F. de 1995. Petrologia das rochas vulcânicas e hipoabissais da Associação Shoshonítica de Lavras do Sul, RS. Tese de Doutoramento em Geociências, Instituto de Geociências, Universidade Federal do Rio Grande do Sul, 338p.

Lima, E.F. de \& Nardi, L.V.S. 1991. Os lamprófiros espessartíticos da Associação Shoshonítica de Lavras do Sul, RS.

Geochim. Bras., 5(1/2): 117-130.

Lima, E.F. de \& Nardi, L.V.S. 1998. The Lavras do Sul Shoshonitic Association: implications for origin and evolution of

Neoproterozoic shoshonitic magmatism in southernmost Brazil. $J$. South Am. Earth Sci., 11(1):67-77.

Lipman, P.W. 1984. The roots of ash-flow calderas in western North America: windows into the tops of granitic batholiths. $J$.

Geophys, Res., 89: 8801-8841.

Lipman, P.W. 1997. Subsidence of ash-flow calderas: relation to caldera size and magma-chamber geometry. Bull. Volcanol.,

59:198-218.

Liz, J.D. de. 2002. Litogeoquimica e química mineral das rochas monzoniticas e diques relacionados da Associação

Shoshonitica Lavras do Sul, RS: Estudo de um caso. Trabalho de Graduação, Instituto de Geociências, Universidade Federal

do Rio Grande do Sul, 98p.

Ludwig, K.R. 2001. ISOPLOT/EX rev. 2.49 - A geochronological toolkit for Microsoft Excel. Berkeley Geochronology

Center, Special Publication, $\mathrm{n}^{\circ} 1,55 \mathrm{p}$.

Marti, J., Ablay, G.L., Redshaw, L.T., Sparks, R.S.J. 1994. Experimental studies of collapse calderas. J. Geol. Soc. London,

151:919-929.

McNulty, B. A., Tobisch, O.T., Cruden, A.R., Gilder, S. 2000. Multistage emplacement of the Mount Givens pluton, central

Sierra Nevada batholith, California. GSA Bull., 112(1):119-135.

Nardi, L. V. S. 1984. Geochemistry and Petrology of the Lavras Granite Complex, RS, Brazil. Doctor of Philosophy Thesis, Department of Geology King's College, University of London, 268p.
Porcher, C.A. \& Lopes, R.C. 2000. Programa Levantamentos Geológicos Básicos do Brasil - Cachoeira do Sul (folha SH.22-Y-A), CPRM/DNPM, (CD-room).

Reischel, J.L. 1980. Mineralizações auríferas associadas ao Complexo Granítico de Lavras do Sul, RS. In: SBG, Cong. Bras. Geol., 31, Anais, p. 1700-1712.

Remus, M. V. D., Hartmann, L. A., McNaugton, N. J., Groves, D. I., Reischl, J. L., 2000. Distal magmatic-hydrothermal origin

for the Camaquã $\mathrm{Cu}(\mathrm{Au}-\mathrm{Ag})$ and Santa Maria $\mathrm{Pb}, \mathrm{Zn}(\mathrm{Cu}-\mathrm{Ag})$ deposits, southern Brazil. Gond. Res. 3(2), 155-174.

Ribeiro, M., Bocchi, P.R., Figueiredo filho, P.M., Tessari, R.I. 1966. Geologia da quadrícula de Caçapava do Sul, RS. Boletim da Divisão de Geologia e Mineralogia DPM-DNPM, 127, 232p.

Santos, E.L., Ramgrab, G.E., Maciel, L.A., Mosmann, R. 1989. Mapa Geológico do Estado do Rio Grande do Sul. DNPM, Porto Alegre. Escala (1: 1000000$)$.

Saunders, S.J. 2005. The possible contribution of circumferential fault intrusion to caldera resurgence. Bull. Volcanol., 67:57-71.

Sircombe, K.N. 2004. AGEDISPLAY: an Excel workbook to evaluate and display univariate geochronologial data using binned frequency histograms and probability density distributions. Comp. Geosc., 30(1):21-31.

Smith, R.L. \& Bailey, R.A. 1968. Resurgent cauldrons. Geol. Soc. Am Mem., 116:613-662.

Soliani Jr., E. 1986. Os dados Geocronológicos do Escudo Sul-riograndense e suas Implicações de Ordem Geotectônica. Tese de Doutorado, Instituto de Geociências, Universidade de São Paulo , 340p.

Stacey, J.S. \& Kramers, J.D., 1975. Approximation of terrestrial lead isotope evolution by a two-stage model. Earth Planet

Sci. Lett., 26:207-221.

UFRGS. 2003. Mapeamento de parte da folha Arroio América (1: 50 000). Curso de Geologia, Instituto de Geociências, Universidade Federal do Rio Grande do Sul, 60p.
O levantamento gravimétrico foi efetuado em uma área de 372 $\mathrm{km}^{2}$ seguindo malha irregular de $2 \mathrm{~km} \times 2 \mathrm{~km}$, que ultrapassou os limites do CILS em até $3-4 \mathrm{~km}$. Foi utilizado o gravímetro digital Scintrex CG-3Autograv (resolução de $5 \mu \mathrm{Gal}$ ), e para cada estação de medida foram efetuadas as correções de rotina para obtenção das anomalias Bouguer, utilizando o valor da gravidade teórica calculada pela Fórmula Internacional da Gravidade de 1967 e a densidade crustal média de $2670 \mathrm{~kg} / \mathrm{m}^{3}$. O mapa gravimético residual foi obtido pela subtração da curva de uma superfície de tendência do primeiro grau, interpretada como representativa do campo gravimétrico regional. Os dados aeromagnetométricos para a mesma região são de Jackson et al. (1973). Estes foram transformados em malha regular pelo método de mínima curvatura, com a aplicação da rotina Ramgrid (Geosoft 2001), adotando tamanho de célula de $250 \mathrm{~m}$ (1/4 do espaçamento médio entre as linhas de vôo). Os dados do IGRF (International Geomagnetic Reference Field), calculados para a época do levantamento no centro da região $\left(30^{\circ} 47^{\prime} 00^{\prime \prime} \mathrm{S}\right.$ e $53^{\circ}$ 52' 00"W) e para uma altitude média de 300 m, são F de 23929 $\eta \mathrm{T}$, I de $-29^{\circ} 52^{\prime} 00^{\prime \prime}$ e D de $-8^{\circ} 05^{\prime} 00^{\prime \prime}$. Subtraindo um nível de base equivalente a média da malha micronivelada, obteve-se o mapa do campo magnético residual. Aos dados gravimétricos e magnetométricos residuais foram aplicadas várias técnicas de filtragem, no domínio da freqüência, como gradientes vertical e horizontal, amplitude e fase do sinal analítico.

Os cristais de zircão foram separados, pelos métodos convencionais, a partir de frações granulométricas entre 0,170 e 0,062 $\mathrm{mm}$. As idades ${ }^{207} \mathrm{~Pb} /{ }^{206} \mathrm{~Pb}$, por evaporação de zircão, foram obtidas no espectrômetro de massa multicoletor Finnigan MAT 262, do Laboratório de Geologia Isotópica - Pará-Iso/UFPA, seguindo os procedimentos de Kober $(1986,1987)$. Em cada amostra, os cristais não-magnéticos de zircão foram analisados em filamento duplo de $\mathrm{Re}$, no modo dinâmico. $\mathrm{O}$ método, conforme Kober (1986), consiste de repetidos ciclos a T crescente 
de evaporação-deposição-ionização de isótopos de $\mathrm{Pb}$. O intervalo de $\mathrm{T}$ de evaporação de $\mathrm{Pb}$ é de $1450^{\circ}-1550^{\circ} \mathrm{C}$, e de $1050^{\circ}$ $1150^{\circ} \mathrm{C}$ para ionização "Coordenadas UTM, Zona $22 \mathrm{~S}$ ". Em cada etapa, as razões isotópicas foram medidas em cinco blocos de 10 ciclos cada. Para correção das razões $207 \mathrm{~Pb} / 206 \mathrm{~Pb}$, foi utilizado o fator de discriminação de massa de $0,12 \% \pm 0,03$ per a.m.u., determinado por análises repetidas do padrão NBS 982. A correção do $\mathrm{Pb}$ comum foi calculada, segundo modelo de Stacey \& Kramers (1975), para a idade do cristal analisado, e o tratamento estatístico dos dados analíticos de acordo com Gaudette et al. (1998). Foram eliminados os blocos de dados com razões ${ }^{204} \mathrm{~Pb} /{ }^{206} \mathrm{~Pb}$ superiores a 0,0004 , para evitar as imprecisões devidas à correção do $\mathrm{Pb}$ comum. Para cada etapa, foram calculados a idade média e o desvio padrão, e a idade do cristal foi então obtida pela média ponderada das idades de cada etapa considerada. A idade da amostra é determinada pela média da idade obtida em, pelo menos, cinco cristais.

Amostras datadas: cristais de zircão prismáticos, não magnéticos e com inclusões e fraturas freqüentes. São subédricos com faces (100) e (101) bem desenvolvidas, e (110) subordinadas.

Kl 97 - monzodiorito equigranular médio, representativo dos termos evoluídos do monzodiorito Arroio do Jacques (MAJ), pouco afetado por re-equilíbrios tardios ou posteriores. Coor- denadas UTM: $225900 \mathrm{~W}$, e $6590580 \mathrm{~S}$. Zircões (8 cristais): incolores a levemente amarelados, com dimensões regulares, $\mathrm{C}$ : $L$ de $3: 1$ a 2:1, zonação concêntrica ocasional nas bordas.

K1 159 - monzonito seriado médio a fino, situado na porção central do monzonito Tapera (MT). Coordenadas UTM: $225890 \mathrm{~W}$, e 6594484 S. Zircão (8 cristais): incolores a levemente rosados, de dimensões variadas, com $C: L$ de $2: 1$ a $5: 1$, zonação concêntrica freqüente nas bordas e núcleos maciços.

Kl 405 - biotita-anfibólio sienogranito (BAS) heterogranular grosso e fino. Coordenadas UTM: 219146 W e 6583578 S. Zircão (16 cristais): incolores a levemente rosados, de dimensões regulares com $C: L$ de 2,5:1 a 4:1, zonação concêntrica ocasional nas bordas.

$\mathrm{Kj} 131$ - biotita monzogranito equigranular médio, representativo da fácies menos diferenciada e situada na porção central do granito Jaguari (Gastal \& Lafon 1998). Coordenadas geográficas: $30^{\circ} 45^{\prime} 36^{\prime \prime} \mathrm{S}$ e $54^{\circ} 07^{\prime} 35^{\prime \prime} \mathrm{W}$. Zircão (16 cristais): incolores a levemente rosados, dimensões variadas com $C: L$ de $1,5: 1$ a $5: 1$

Manuscrito A-1575

Revisão aceita em 14 de junho de 2006 